\title{
Reshaping energy policy based on social and human dimensions: an analysis of human-building interactions among societies in transition in GCC countries
}

\author{
Ali Ghofrani ${ }^{1}$, Esmat Zaidan ${ }^{1 凶} \&$ Mohsen Jafari ${ }^{2}$
}

Without major structural changes, social sciences can potentially bolster economic diversification and strategic planning efforts in developing countries. This article presents an analysis of a set of human-oriented dimensions to enhance energy policies associated with the building sector in developing countries with similarities to the Gulf Cooperation Council union (GCC). A clear understanding of human dimensions in the GCC union's energy policy is crucial due to social complexities and large numbers of expatriate communities and migrant workers with unknown cultural, behavioral, and financial diversities with respect to local communities. This study evaluates the correlations of demographic, socioeconomic, and behavioral dimensions with human-building interactions to identify the main contributors that create discrepancies in human habits, well-being, motivations, responsibilities, and energy use based on a sample of 2200 respondents in Qatar. Moreover, this study is extended to explore human indoor comfort perception dependencies with building features. Behavioral associations with financial drivers, including energy subsidies and demand response programs, are investigated. The patterns in the data are analyzed and attributed to applications in energy policy concerning awareness, social well-being, and interventions. The sample is clustered into various consumer classes, and a feature importance analysis is conducted via machine learning methods to find the key contributors to consumer behavior. The outcomes show profound insight into how human factors influence consumption, consequence awareness, self-responsibility, habits, norms, and comfort perception in residential and work environments. The findings of this study can assist decision-makers in creating targeted strategies to enhance the efficacy of energy policies and improve sustainability performance indicators.

\footnotetext{
${ }^{1}$ Department of International Affairs, College of Arts and Science, Qatar University, Doha, Qatar. ${ }^{2}$ Department of Industrial and Systems Engineering, Rutgers University, Piscataway, NJ 08854, USA. 凶email: ezaidan@qu.edu.qa
} 


\section{Introduction}

wing to widespread global challenges in the energy sector, it is critical to identify the role of human and social dimensions regarding a major threat to health, economic prospects, and basic resources of billions of people (Niamir et al., 2018). The human and social factors have been recognized as critical drivers in energy policy and planning worldwide. The building sector is critical among human dimensions because, in addition to major economic and environmental impacts, it accounts for approximately $40 \%$ of annual global GHG emissions (Niamir et al., 2018). Therefore, it is important to develop an intelligent system that can assess electricity consumption (Moghaddasi et al., 2021) by significantly monitoring consumer interaction (i.e., human behavior) with the energy system (Qiao and Yin, 2021; Zhang et al., 2020; Ming et al., 2020). Then, it will be possible to obtain a stronger economy and a better indoor environment throughout the country. Accordingly, energy and buildings have attracted considerable political and scientific pressure, and the evaluation of energy demand in buildings has become increasingly acute in the last 15 years (Delzendeh et al., 2017). The endeavors undertaken to curtail energy use (and GHG emissions) are myriad and diverse. These efforts, however, are most inclined toward techno-economic assessments (Sembroiz et al., 2018) and legislation to successfully actualize these nifty practices (Buildings, 2012). Unfortunately, although a crucial factor, efforts that directly address human-building interactions (HBIs) are still not among the dominant strategies in the field (Labanca and Bertoldi, 2018). Undoubtedly, occupants, directly and indirectly, interact with the building environment and equipment (Angizeh et al., 2021a); therefore, failures to incorporate human dimensions into energy decision-making derail efforts and create performance gaps (Bertoldi, 2019; Jafari et al., 2020). This fat makes HBIs one of the strongest links in the building energy efficiency and conservation equation (B and Lalanne, 2017).

The existing literature has determined that human factors are partially responsible for the variance in energy use (Jia et al., 2017; Zhao and Magoulès, 2012). For instance, some case studies have demonstrated that occupants with 'wasteful workstyles' consume up to double the energy of nonwasteful, "austere" coworkers (Lin and Hong, 2013). Furthermore, it is well-known that the comfort preferences of occupants vary due to variables such as age, gender, and psychological and cultural factors (Karjalainen, 2007; Parsons, 2002); this variation has become a major predicament for the operation of commercial buildings (Nematchoua et al., 2019; Appel-Meulenbroek and Danivska, 2021; Nazemi et al., 2021b; Zaidan et al., 2021) such as offices because it is not possible to cater to each individual at a granular level. More precisely, some researchers argue that human factors in commercial buildings represent the 'dark side' of energy use (Masoso and Grobler, 2010). Thus, the implications of occupant behavior are highly stochastic (Hong et al., 2017; Thiaux et al., 2019), and therefore require additional research. Consequently, a recent study (D'Oca et al., 2018a) demonstrated that technology investments alone do not necessarily guarantee low or net-zero energy or higher comfort perception in buildings.

Due to the oil crisis in OECD countries in the 1970s (Bertoldi and Economidou, 2018), energy efficiency has been recognized as a critical factor for promoting energy security. Researchers have highlighted the potential for considerable energy savings. Moreover, studies have proven that energy-efficient technologies can result in the provision of the same services but with significantly lower energy input. In addition, the concept of the 'energy efficiency gap' was introduced. This concept refers to the difference between the cost-optimal level of energy efficiency and the level of energy efficiency implemented by end-users, i.e., the untapped energy efficiency potential. According to Sorrel et al. (Sorrell and Scott, 2000), the following are the barriers to energy efficiency: (i) risk, (ii) imperfect information, (iii) hidden costs, (iv) access to capital, (v) split incentives (Nazemi et al., 2021a), and (vi) bounded rationality. Similarly, Cagno et al. (2012) classified the barriers by combining economic factors, functions, and the type of actors as follows: barriers combining the type of actors, function, and economics into (i) market, (ii) government/politics, (iii) technology/service suppliers, (iv) designers and manufacturers, (v) energy suppliers, (vi) capital suppliers, (vii) organizational, (viii) economic, (ix) behavioral factors, (x) competence, and (xi) awareness. However, one common characteristic of all presented classifications is that end-user behavior is regarded as a fundamental barrier. Remarkably, the end-users behavior is seen as a barrier at both the individual and organizational levels. Such barriers can be eliminated only by implementing policies and policy packages aimed at enhancing energy efficiency (Victor and Edenhofer, 2014; Masson-Delmotte et al., 2019; Kern et al., 2017; Blok et al., 2020; Zaidan and Abulibdeh, 2020). To date, different regional, national, and international initiatives have been taken and are mainly led by the European Union. Furthermore, Sofia Tsemekidi et al. (Tzeiranaki et al., 2019) examined the trends in residential energy consumption in the European Union by considering energy consumption targets set by the EU 2020 and 2030 Energy and Climate Strategies. The authors analyzed energy consumption determinants (e.g., household and building features, climate, population growth, and economic growth), energy efficiency policies, and data on energy consumption. They determined the indicators to show the influence of particular determinants on energy consumption and proposed a new indicator to show a correlation between policy and technological changes and energy trends.

Concerning stochasticity, variances in energy use can be addressed only through case-specific assessment and research because occupant behavior cannot be determined a priori (D'Oca et al., 2018a), implying that valid conclusions can be drawn only through empirical data based on case studies, surveys, and real behavioral data (Heydarian et al., 2020). Rinaldi et al. showed how critical factors behind human behavior can be obtained via surveys (Rinaldi et al., 2018). Moreover, this study demonstrated that building characteristics play a major role in occupant behavior as a main source of stochasticity. For instance, with the increasing age of a building, occupant behavior shifts toward a higher temperature set point and increases usage of heating systems, leading to higher energy consumption (Rinaldi et al., 2018). This finding highlights the fallacy of achieving a fixed set-point temperature and of assuming that occupants' action is independent of building characteristics. Consequently, the predicted energy consumption is significantly different from the observed energy consumption.

Numerous studies have highlighted this discrepancy (Calì et al., 2016), noting that actual energy consumption can be three times higher than predicted energy consumption (Delzendeh et al., 2017). While researchers aim to mitigate this gap, among the most pertinent and recent studies of parameters that influence occupants' energy behavior, only $10 \%$ of them focused on social and personal factors. Thus, it is imperative to adopt a multidisciplinary approach to energy consumption with sociopersonal parameters through psychological cognitive-behavioral methods (e.g., theory of planned behavior, cognitive complex theory, and cognition as a network of tasks) (Delzendeh et al., 2017; Tzeiranaki et al., 2019). This study follows the same multidisciplinary approach; however, it is essential to realize its unique difference. 
More specifically, the goal of this study is to determine all aspects of building sustainability, including energy efficiency and an optimum comfort condition for building occupants. The optimum comfort condition is critical because of the evidence obtained from case studies. First, the "Desire for Control" (Schakib-Ekbatan et al., 2015) over ambient environmental conditions, such as temperature or indoor air quality, has a strong impact on the well-being of employees. Second, it is critical to consider occupants' thermal preferences because it has been proven that in buildings where comfort conditions are controlled at the group or zone level, productivity losses are common (Mofidi and Akbari, 2017). Therefore, any productivity loss is an economic loss, and any investment toward achieving optimal comfort of employees reaps economic benefits (Carr et al., 2017).

However, an economic factor hinders optimal personal comfort, which is, more specifically, the tradeoff between energy consumption and human well-being. Although thermal comfort is a paramount feature of sustainable building performance, there is no specific framework that incorporates both of these dimensions of sustainable building performance (Nikolopoulou and Azar, 2015). A common practice is measuring thermal comfort based on whether people are satisfied (Lu et al., 2018). The specific metric typically used is the predicted percentage of dissatisfied (PPD) people, as defined by the American Society of Heating, Refrigerating, and Air-Conditioning Engineers (ASHRAE) (Sghiouri et al., 2018; Sustar, 2020; Földváry Ličina et al., 2018; Lee et al., 2018). ASHRAE has also developed several codes and regulations pertinent to thermal comfort to which a building must conform. However, balancing the aforementioned tradeoff is highly complicated because of the challenges associated with distinguishing between different occupant profiles; each occupant's profile is different because of a variety of demographic variables, such as age, ethnicity, and working class, and each profile exhibits a different pattern of using and interacting with the environment (Nikolopoulou and Azar, 2015).

Furthermore, the behavioral patterns are not consistent; for instance, open windows during summer $40 \%$ of the time, despite outside temperatures being higher than inside temperatures, result in heat gains offset by nighttime ventilation. Similarly, there is the dilemma of data acquisition: the word 'survey' may connote a nonvaluable commodity but acquiring it is challenging since permission for surveys cannot be obtained for every building. Moreover, these subjective data are integral for interpreting behavior profiles, particularly when they are linked with data from building sensors (Schakib-Ekbatan et al., 2015). In brief, there are too many challenges to be solved by one study. Therefore, it is necessary to design a precise approach to enable a comparison. In addition, Hewitt et al. directly linked the social variables of humans to a specific energy efficiency practice in a building (Hewitt and Wang, 2020). They demonstrated that 'the chances of taking an energy audit decrease by $43 \%$ if the occupant is a tenant,' quantifying a human social pattern by considering a building efficiency aspect. Similarly, some studies established a strong correlation between the precise actions of an occupant (building temperature set point) and building age (Rinaldi et al., 2018). Even though the assessment and inclusion of HBIs and behavioral factors at the building operation and design level are inevitable, they cannot completely fill the gaps (Thompson et al., 2021). Tianzhen et al. (Hong et al., 2020) investigated the correlation between personality types and behavior related to interactions with colleagues, environment control systems, and energy sharing. The purpose of the study was to explore how perception attitudinal factors, building-related contextual factors, and demographics impact HBI behaviors by applying a machine learning technique called association rules. The study results indicated that the most significant factors that impact the HBI behaviors of occupants are group dynamics, control feature accessibility, and country. Moreover, the study explored building design and operation and proposed a policy aimed at promoting environmentally and socially preferred HBI behavior in shared offices. Milad Afzalan et al. (2019) developed a self-configuring event detection framework aimed at determining the changes in operational states of appliances. More precisely, this framework is optimized to autonomously learn loads' contextual characteristics from the environment and to subsequently adapt parameters of event detection. This framework combines proximity-based motif matching for detecting events and automated clustering for determining recurring motifs. Recurring motifs represent transient power draw signatures of the appliances in a certain environment. With this framework, smart home applications are trained by populating motifs to infer occupants' activities and appliances' operations. Accordingly, the framework significantly facilitates interactions between buildings and humans. In addition, Simona et al. (D'Oca et al., 2018b) conducted a study that demonstrates the innovative knowledge of the social sciences regarding building technology adoption in shared contexts. Accordingly, such insights can improve perceived environmental satisfaction and increase the effectiveness of personal indoor climate control in offices. Consequently, operational energy costs are reduced, and the productivity of office workers is improved. Shan $\mathrm{Hu}$ et al. (Hu et al., 2019) analyzed case studies of the building sector's energy efficiency policies in China. The study focused on the target design, implementation, and impact of these policies. More precisely, the authors investigated solar water heaters, incentives for promoting energy efficient lighting bulbs and home appliances, green building labeling, and building energy efficiency standards/codes. The results indicated that the impact of energy efficiency policies in the building sector is limited by multiple factors. The authors provided recommendations for achieving emission and energy consumption reduction, proposing to shift the policy to outcome management instead of process control. Outcome management should include both the energy efficiency of the operational system and final energy consumption. In addition, the focus should be shifted from energy-efficient products and standards to performing energy consumption management and energy consumption quotas. Konstantakopoulos et al. (2019) proposed the inclusion of incorporated humans-in-the-loop modeling via an interface to enable building managers to cooperate with occupants and offer incentives for behavior that is energy efficient. In addition, the authors propose a gamification approach as a novel framework for smart building infrastructure with the goal of motivating human occupants to consider personal energy usage and to have positive effects on their environment. Finally, they developed an innovative benchmark utility deep learning framework that includes robust estimations of occupant actions regarding energy efficiency.

High decision-making levels must analyze and determine the role of social and human factors and their interdependencies (Sovacool, 2014). Therefore, human actional phases, such as predecision, preaction, action, and postaction phases, must be identified for different socioeconomic factors to establish energy transition targets (Bamberg, 2013). Behavioral factors such as social norms, personal norms, emotions, attitudes, trust, and skills (Zhao et al., 2017; Lacroix and Gifford, 2018) can be a basis for integrating individuals' behavior and needs in energy decisionmaking and, in turn, social, economic, and environmental concerns at macroscales. For instance, the policymaker can leverage the insight to establish new social and personal norms and improve awareness in energy consumption behaviors through new capabilities, opportunities, and motivations. It is essential to distinguish between energy efficiency programs that respond to 
continuous and permanent changes in energy usage and temporary demand response (DR), which is generally paid through incentives and exposure to time-varying electricity pricing. Managing a DR efficiency by implementing energy efficiency programs can lead to a reduction of $157 \mathrm{GW}$ in non-coincident summer peak demand by 2030 , or more precisely $14-20 \%$ under estimated levels (Bertoldi et al., 2013). In addition, the knowledge can assist the decision-makers to identify and prioritize underprivileged communities for energy subsidies and financial incentives to improve the quality of life, relieve the financial burdens (Kontokosta et al., 2020), and even improve the efficacy of energy efficiency programs (Drehobl and Ross, 2016). However, human-oriented strategies must be accompanied by sociotechnical and techno-economic assessments of advanced technology and infrastructure requirements.

Social and behavioral traits are complex phenomena that must be taken as critical components of energy strategic planning (Safron and DeYoung, 2021; Singh and Yassine, 2018). Complexities grow exponentially when a community entails highly diverse demographics and ethnicities, as is the case in dynamic societies with a considerable proportion of migrant workers and expatriates, such as Gulf Cooperation Council (GCC) countries (Abul et al., 2019; Hassine and Harrathi, 2017; Zaidan et al., 2019). Such societies continually evolve, and the decision-makers are not clearly identified to the population. Owing to the rapid social changes in countries similar to the GCC union and a lack of empirical evidence, the specific behavioral analysis must focus on various mixtures of human factors that influence energy strategies, particularly in the building sector. Over the past half-century, underdeveloped GCC countries have been transformed into societies with high economic standards because of considerable reserves of hydrocarbons. Western influences have also brought about architectural changes. To achieve showcase modernity, detached houses with glazed facades were introduced. However, this trend increased energy demands due to poor insulation and high levels of heat gain, as such houses are not adjusted to the local climate (Lahn et al., 2013). It is also important to recognize that low energy prices in the GCC have enabled such architectural trends, which resulted in exceptionally high energy consumption rates among the residents (Alalouch et al., 2016).

In this study, a sample of 2200 respondents in Doha, Qatar, is targeted to investigate the interdependencies in HBIs through an empirical and analytical analysis. Qatar is a GCC founder member (Alfadala and El-Halwagi, 2017) that adequately reflects the demographic, economic, and political context of the region with a growing and dynamic population (90\% expatriate and migrant worker communities). In this research, we first demonstrated why the role of humans is critical in the building energy sector in rapidly developing GCC countries. Next, the distribution of the survey results in terms of demographic, socioeconomic, behavioral, and technical factors was determined. In so doing, we categorized relevant empirical studies in the literature to introduce the key survey elements used in the analysis. The building properties of all the respondents' dwellings and workplaces are presented, as well as other HBIs, such as perceived thermal comfort, building operation interruptions, and the role of the quality of the indoor environment on human well-being and work performance. Financial factors, such as the role of electricity pricing on ratepayers' consumption, monthly electricity bills, and ratepayers' willingness to participate in behind-the-meter practices and DR programs, were assessed, and the main drivers encouraging user participation were identified. The sample was clustered into two different consumer classes based on the EUI of their dwellings using the $k$-means clustering method. A feature importance analysis based on a random forest classification was conducted to identify the main factors impacting human energy consumption patterns. The sample data were subsequently classified based on the main human-oriented factors to determine the associations between the survey elements. The results are elaborated in the paper, which discusses recommendations to integrate human dimensions into energy policy and enhance the outcomes of strategic plans for the built environment sector in the GCC region.

\section{Case study and motivations}

This study was conducted in Doha, Qatar. The state of Qatar, as a member of the GCC union, has placed the promotion of a knowledge-based economy at the heart of its development strategies, prioritizing sustainability and social well-being. In the last two decades, Qatar has experienced one of the fastest economic growth rates, which directly influences the country's energy demand. This economic expansion is clearly observed in Qatar's population growth, annual electricity consumption, and the total number of installed electricity meters in the commercial and residential sectors (Fig. 1).

However, the country depends exclusively on hydrocarbons for energy supply. The heavy reliance on conventional sources of energy results in increasing economic and environmental costs. Therefore, as part of its vision, Qatar considers the environmental objectives and the promotion of strategies to curb energy demand without a major structural change to its economy core as a priority. In this regard, a viable solution could be forming a broad (a)

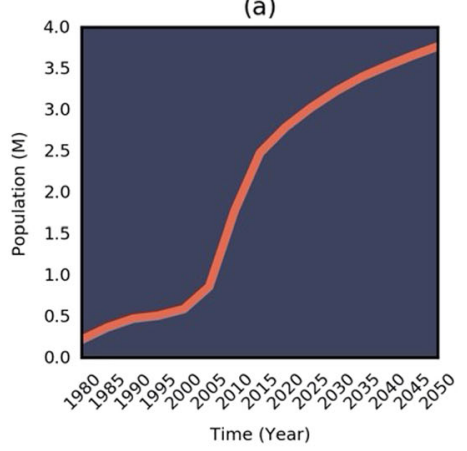

(b)

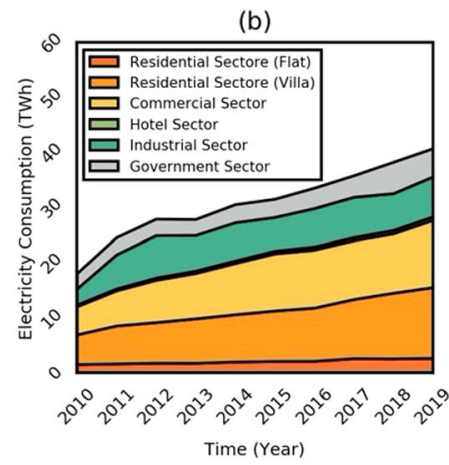

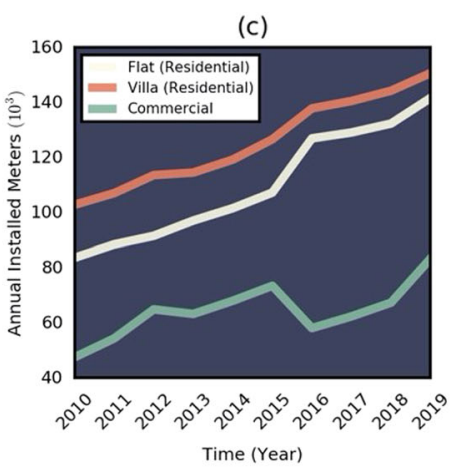

Fig. 1 Economic growth of Qatar. Qatar's increasing economic expansion, as reflected by a historical and projected population growth by 2050 (UNESCWA, 2017), b sector-wise annual energy consumption, and $\mathbf{c}$ the total number of installed electricity meters in residential and commercial buildings. 

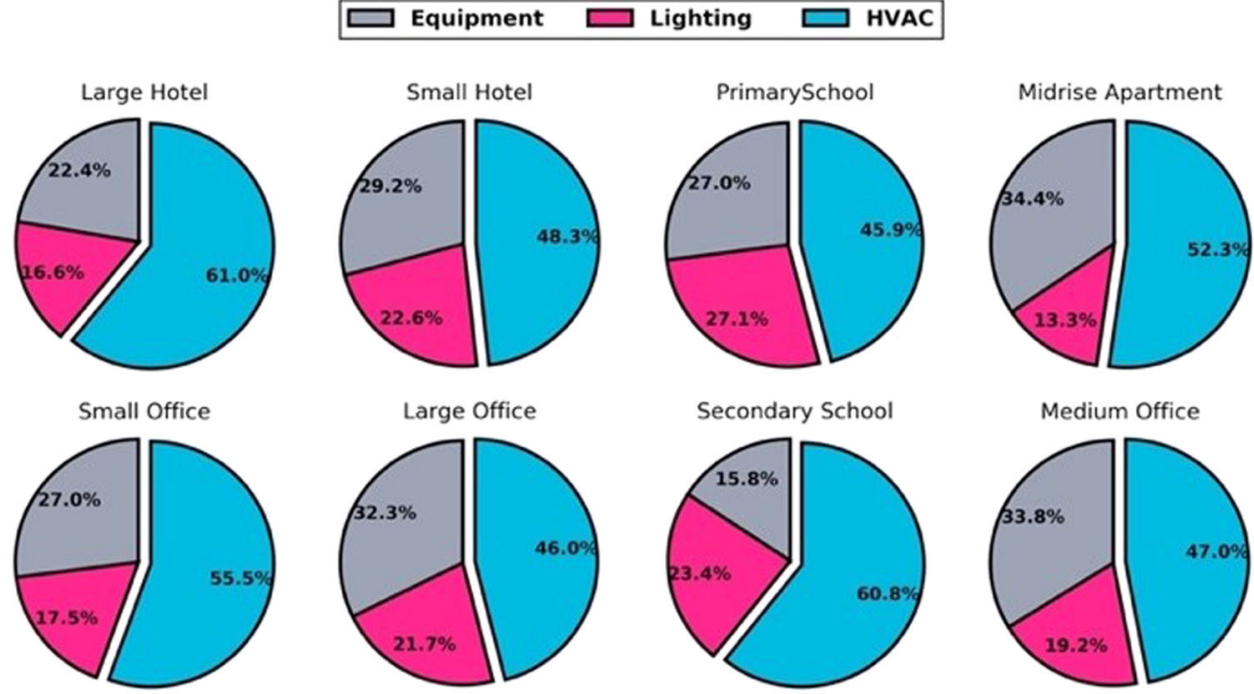

Fig. 2 Distribution of urban building energy consumption. The breakdown of the main building energy end-use for commercial and residential buildings in Doha based on EnergyPlus simulations showing the dominant role of the cooling load.

range of energy policies around social and human dimensions, particularly regarding building electricity demand, by knowing the fact that human-driven factors account for a substantial portion of the load and sources of uncertainty in the electric power industry. However, this strategy cannot be determined based on a clear roadmap for Qatar since the population consists of $90 \%$ expatriate and migrant workers with diverse and unknown socioeconomic, cultural, and ethnic traits.

Furthermore, due to Qatar's arid climate, the cooling load, which is closely linked to HBIs, is the largest and most uncertain end-use of the building sector. Figure 2 demonstrates a set of EnergyPlus building simulations (Polese and Roth, 2016) for eight different commercial and residential buildings modeled based on Doha's weather condition and building codes. According to the results, for commercial and residential buildings, $46-61 \%$ of the annual electricity is dedicated to the cooling load. Therefore, the analysis of possible human interdependencies with the cooling load becomes a major concern because the cooling load can unlock saving potentials because it is flexible and controllable. Aside from its considerable role in electricity consumption, air conditioning in arid regions heavily influences indoor thermal comfort and human well-being. Notably, human-building interdependencies must not be limited to HVAC load, while human engagement with other enduses, particularly indoor lighting and appliances, is also of paramount importance.

An adequate understanding of HBIs and human perceptions in built environments can offer a set of new targets in energy policy in Qatar and other countries in the region:

- Improving energy consequence awareness and establishing new personal and social norms by purposefully targeting the society based on demographic and socioeconomic factors.

- Improving social well-being in indoor environments by understanding human perceptions and choices for all social communities. This insight can help decision-makers prioritize subsidies and financial support in strategies, such as incentives for building retrofits, based on community needs.

- Developing interventions such as personalized electricity pricing or coercive actions to curb demand based on ratepayers' consumption behaviors.
- Identifying the key elements to incentivize the consumer to participate in energy efficiency programs and strategies such as DR programs.

- Understanding the impact of deviation from indoor comfort zones on the human quality of life perception to create tangible guidelines and recommendations for the design and control of built environments.

Since Qatar is a diverse society with a broad range of demographic characteristics, the outcome of the above targets can mitigate the uncertainties associated with human factors in energy policy and close the performance gaps in future plans.

\section{Methodology and survey structure}

This study aimed to investigate the role of human and social dimensions in enhancing the efficacy of energy policy and performance gaps in the building sector in Qatar and the GCC union. Thus, a survey analysis among a sample size of 2200 subjects was conducted to assess various demographic (age, gender, and ethnicity) and socioeconomic (household income, expenses, marital status, and employment) traits and their interdependencies with behavioral factors and human interactions in built environments. Quantitative and qualitative measures were implemented to determine indoor thermal and lighting comfort and indoor environment preference, and their influence on respondents' well-being and productivity were among the main target elements in the study. Respondents were asked about their habits and routines in interacting with the building, including window use and thermostat switching, to identify associations within the set of features. Other psychological and behavioral factors, such as awareness of consequences, responsibility factors, motivations, and attitudes, were investigated, and existing intercorrelations were investigated.

To identify the main contributors to the discrepancies in consumption behaviors, building features such as construction year, floor area, and building type, along with monthly electricity bill data, were collected to estimate and compare the respondents' energy use intensity (EUI). Based on the estimated EUI values, the subjects were then clustered into two categories of high and low consumers using the $k$-means clustering method. A feature importance analysis was conducted afterward to identify the main demographic, socioeconomic, and behavioral features that cause discrepancies in energy consumption categories. As another 


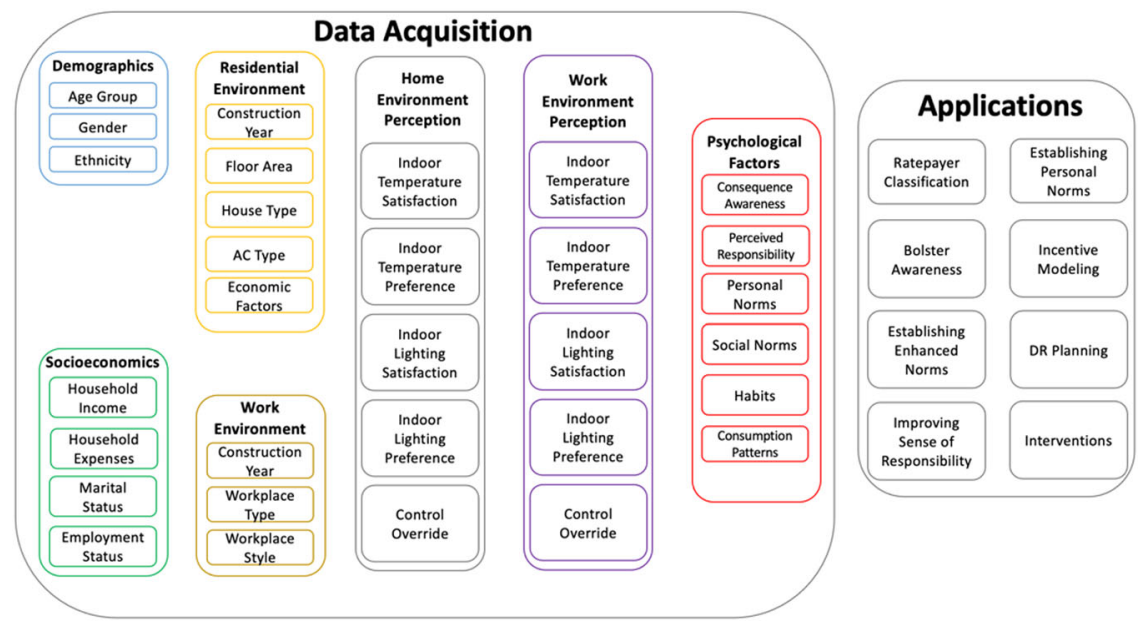

Fig. 3 Structure of the main factors embedded in the survey study. The survey framework is composed of the data acquisition of human dimensions and building properties of the sample as a baseline to gain insight into different applications in energy decision-making.

important building feature, information on the air conditioning system was acquired, and the associations with behavioral factors were investigated. Furthermore, financial drivers such as the impact of energy subsidies and rate structures on energy consumption along with motivations for participation in DR programs were fully investigated. The outcome of this study was then used to provide recommendations and guidelines to bolster the energy policy of the building sector in GCC countries. Figure 3 shows the overall structure of the main factors embedded in the survey study and the human-oriented applications that are based on specific demographic and socioeconomic characteristics of the migrant and local communities within society. In this section, the main components of the survey study are presented, the overall patterns are described, and the importance of the proposed survey elements are justified with similar studies in recent literature.

Demographic factors. Qatar has a young population mostly composed of expatriate communities. Based on Qatar's census data in $2015, \sim 39.8 \%$ of the population resides in the municipality of Doha. The male population in Doha is dominant, and $~ 85 \%$ of the population is aged 15-64. Figure 4 shows the main demographic factors of the sample with a right-skewed distribution in terms of age group (dominated by the 25-34 age group with $42 \%)$, a close proportion of males (51\%) and females (49\%), and different ethnicities categorized by Qataris (40\%), Arab nationalities other than Qataris (28\%), Asian (11\%), North American (9\%), Indian (6\%), European (5\%), and $1 \%$ of the sample as other nationalities. In addition to the fact that for any survey analysis, such fundamental insight is necessary, and there are studies reporting direct interdependencies between demographics and energy-building interactions. For instance, the following patterns are reported: correlations between gender and thermal comfort (Sintov et al., 2019); gender and age correlations with thermal comfort preference and reactions to indoor environment changes (Schweiker et al., 2018); demographics and willingness association with DR strategies (Nilsson et al., 2018); family age structure associations with home energy consumption patterns and adoption of new energy-related technologies (Mills and Schleich, 2012); associations and disparities between spatial, racial/ethnic and EUI (Reames, 2016); ethnicity and financial burden of home energy expenses (Drehobl and Ross, 2016); ethnicity and home energy efficiency (Bednar et al., 2017); and demographic factors and willingness to accept an energy audit (Hewitt and Wang, 2020). Table 1 shows a summary of these studies, presenting the interacting factors and related findings.
Socioeconomic factors. It is expected that there will be correlations between socioeconomic processes and human-oriented factors interacting with the built environment. Drehobl and Ross demonstrate interdependencies between household income level and energy expenses and how targeting low-income homes can become more energy-efficient than targeting average homes (Drehobl and Ross, 2016). In another survey study among homeowners and tenants, Franke and Nadler showed that homeowners are more concerned about energy performance certificates and home energy efficiency than renters (Franke and Nadler, 2019). Identifying low-income and renter communities could improve strategic planning to benefit the entire society with regard to environmental pollutants and reduce the burden of energy expenses in underprivileged communities. Bednar et al. show patterns between income levels and utility bill payments, indicating that although $14 \%$ of high-income families and $40 \%$ of low-income families miss their bill payments, the likelihood of service shutdown is seven times higher among low-income households, while low-income families consume more energy per unit area (Bednar et al., 2017). Bradshaw et al. reviewed the relationship between home weatherization treatments and household income level (Bradshaw et al., 2016). Their results indicate that practices such as the installation of programmable thermostats, attic insulation, and envelope air sealing offer more savings for low-income households. Reames reports a positive correlation between household income and education level with home energy efficiency (Reames, 2016). Based on the information of 1670 zip codes, Boucher examined interdependencies between sociospatial tendencies and temporal trends associated with the per capita incidence of home energy audits (Boucher et al., 2018). The results indicate that in addition to political affiliation, among highly educated households, energy audits occur more frequently, while high-income families are less inclined to participate in energy audits. Salvo evaluated the associations between different socioeconomic segments and water/electricity use patterns in tropical weather conditions and demonstrated that low-income households consume more water, whereas high-income end-users consume more electricity in the event of a temperature increase (Salvo, 2018). Kontokosta et al. evaluated the influence of home energy efficiency on households' energy cost burden (ECB), demonstrating that among low-income families, ECB is $\sim 7 \%$, whereas this number is $2 \%$ on average for higher-income families (Kontokosta et al., 2020). Their analysis shows that on average, an annual savings of $\$ 1500$ could be achieved by leveraging low-cost energy-oriented home improvements. Nilsson et al. evaluated the 

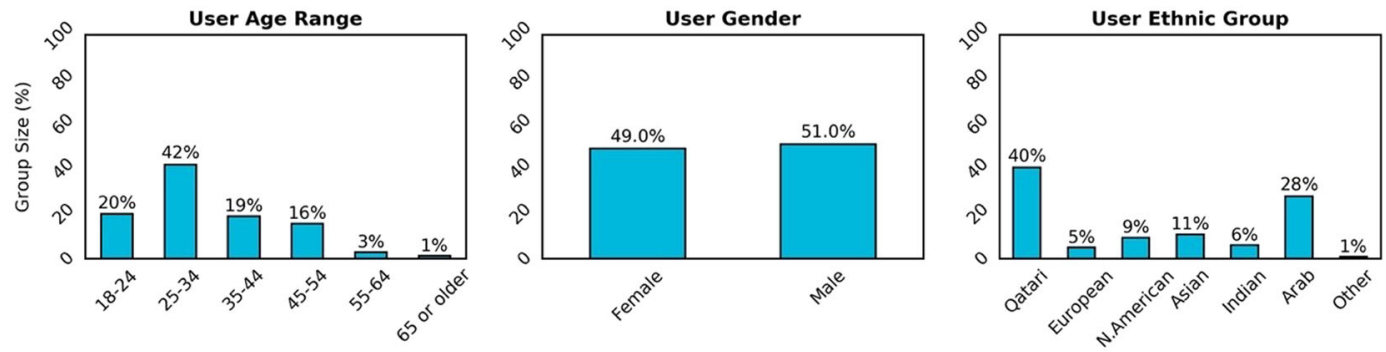

Fig. 4 The distribution of the sample's demographic factors.

efficacy of DR practices and demonstrated that the performance of such programs depends on the household age structure (Nilsson et al., 2018). In their study, families with children show less flexibility with regard to shiftable loads during peak hours. In another study, Guerra-Santin et al. showed correlations between respondents' employment status and thermal comfort expectations (Guerra-Santin et al., 2016). A comparison of the above studies is shown in Table 2.

In our analysis, knowing the importance of economic drivers in human-building interactions, we gathered information about households' income, monthly expenses, marital status, and employment status to identify any significant interdependencies among the presented features. Figure 5 shows the distribution of the above factors with a right-skewed household income and monthly expenses, a close proportion of single and married subjects, a dominant ratio of renters, and the finding that most subjects are employed in the private or public sector.

Human attitude and drivers. Human attitudes toward energy, including consequence awareness, motives, and perceived responsibility, are regarded as irrefutable drivers in energy systems, particularly in the building sector. In this work, respondents were asked about their awareness of the consequences of climate change, home energy efficiency motivations, and self-perceived responsibility factors (Fig. 6). The results show that $\sim 44 \%$ of the sample is either not sure or not even concerned about climate change. Most subjects (40.85\%) believe that the main driver for possible home energy efficiency improvements is financial, whereas $24.1 \%$ are concerned about social benefits, and $29.1 \%$ are concerned about environmental benefits. In addition, respondents' views of the factors that can improve the sense of responsibility among society was evaluated. The results show that $40.8 \%$ of the sample believe that coercive actions and law enforcement are the most effective means, while media, financial incentives, and academic education are the next most effective methods. Finally, $65 \%$ of the respondents had a positive selfperception of consuming water and electricity at their workplace, while $29 \%$ reported that they did not act responsibly.

The aforementioned factors are widely discussed in the literature. Identifying the main behavioral drivers and human attitude factors in energy efficiency and human-building interactions could provide the appropriate insight for energy policies associated with strategies such as targeting population segments to improve awareness, incentive modeling, and planning for DR programs. For instance, emphasizing high participation in DR programs does not necessarily result in higher energy savings, whereas performance incentives and motivating strategies seem to be more effective in DR participation (Ida et al., 2019). Based on a national survey, Biresselioglu et al. evaluated the main humanoriented drivers, including perception and awareness, in household energy use patterns (Biresselioglu et al., 2019). The survey targets subjects' knowledge of energy efficiency solutions along with other factors such as preference and security concerns. The results show that less than half of the subjects use their prior knowledge in energy efficiency ratings when interacting or selecting appliances. Awareness regarding air conditioning technologies was $<50 \%$, whereas awareness of the use of renewable energy resources in water or space heating was $<5 \%$. Subjects' main concerns in energy-saving-related topics were financial drivers and energy bills. Al-Marri et al. investigated the ongoing patterns of energy use in Qatar and consumer awareness regarding renewable energy (AlMarri et al., 2018). The results indicate that energy efficiency concerns are unrelated to economic drivers in Qatar due to the existing energy subsidies, while $\sim 70 \%$ of the respondents are unaware of their energy and water consumption. In contrast, more than $80 \%$ of energy subsidy beneficiaries believe in the importance of saving energy, and more than half of the subjects indicated that environmental challenges are their main concern and admitted the fact that education level impacts their energy awareness. GuerraSantin et al. used monitoring data to evaluate human attitude factors in building energy conservation (Guerra-Santin et al., 2016). The results show that the subjects are more inclined to save energy when their actions do not create inconveniences. In addition, building conditions and user control opportunities are likely to influence human attitudes, while respondents who are not concerned about energy efficiency perceive thermal comfort as an important driver. Koupaei evaluated respondents' perceptions regarding the main drivers of using smart thermostats and showed that saving energy and money is the least important concern among users, whereas comfort, ease of use, and installation were the main drivers (Malekpour Koupaei et al., 2020). Hong evaluated a set of crucial issues concerning building energy efficiency concepts, applications, and occupant behavioral factors (Hong et al., 2017).The findings indicate that the behavior of energy-aware users can result in up to $20 \%$ energy savings in buildings and that nonmonetary information-based interventions can potentially lead to noticeable savings. Franke et al. demonstrate that financial drivers are the most important factor for homeowners to adopt energy efficiency practices, along with the fact that energy awareness positively impacts homebuyers' decision-making when purchasing a house (Franke and Nadler, 2019). Darby evaluates the drivers that might influence users' decisions to participate in DR programs (Darby, 2020). In this study, in contrast to the dominant strategic perspectives in designing DR programs based on financial incentives and technical considerations, comfort and user experience are reported as important factors by users. In another study on DR strategic planning to reduce winter peak demand (Srivastava et al., 2020), the main behavioral factors that can encourage human participation in DR programs were assessed. The study showed that financial drivers and convenience factors, such as day of the week for curtailment, pose the greatest concern. In addition, users' willingness to participate in DR programs is positively correlated with awareness, privacy, homeownership, and age. It has also been demonstrated that financial incentives are more effective than environmental incentives in improving demand flexibility (Nilsson et al., 2018). 


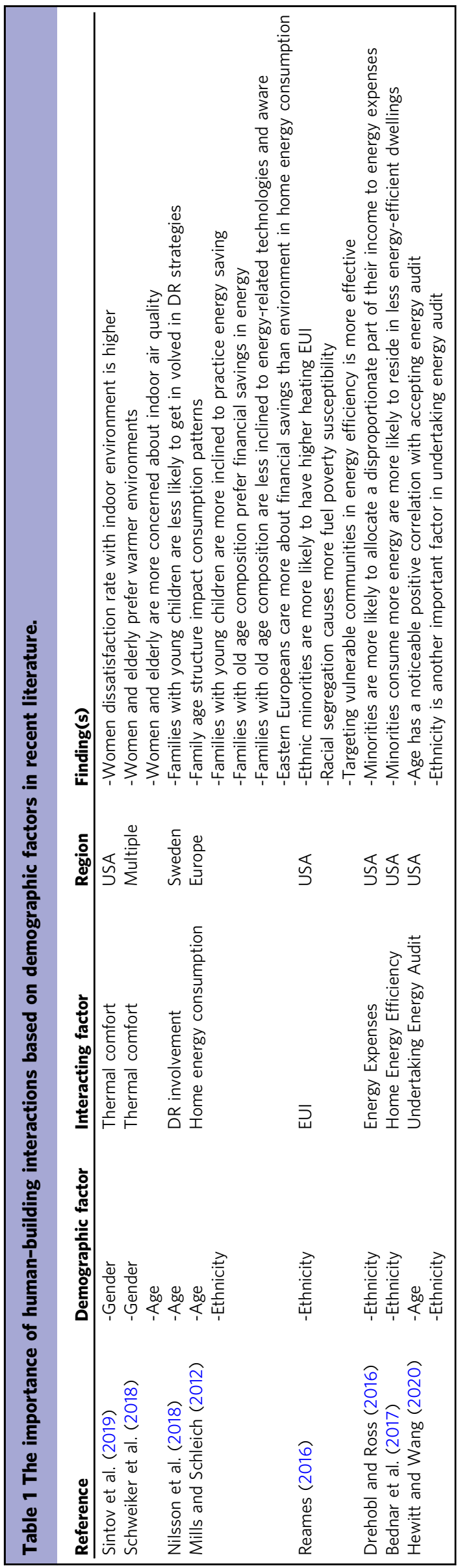

Residential building properties. In this part of the study, respondents were asked about their home construction year, type, floor area, air conditioning system, and whether their home was considered modern in terms of architecture and equipment. Such information is crucial in understanding human-building interactions because it can directly influence human well-being, comfort, and consumption patterns. For instance, in old housing, consumers set the heating temperature at higher setpoints, use the heating system for a longer period of time, and experience greater discomfort. These facts also indicate that upgrade incentives might create discrepancies in expected strategic outcomes when decision-makers do not consider human behavior and building conditions in their analysis (Rinaldi et al., 2018). It is also expected that air conditioning technology and building type/ condition exhibit interdependencies with consumption patterns and human comfort. The building floor area was also incorporated in the analysis to normalize monthly energy consumption per unit area to find an equivalent for EUI. Figure 7 shows the distributions of the conditions and features of the sample's residential buildings. As shown here, most buildings were constructed after 1990 with a left-skewed distribution toward recent years. In addition, although the floor area distribution is rightskewed, the end tail covers a considerable number of villas with a floor area $>500 \mathrm{~m}^{2}$. Furthermore, the distribution of home types in four main categories (villa, flat, Arabic style, and part of unit) and home-style is presented. Most of the building types are villas and flats, and more than $65 \%$ of the homes are regarded as modern buildings. Finally, based on the distribution of the different air conditioning types, wall-mounted air conditioners and central air conditioning systems dominate the other types.

Home environment, consumption behavior, and financial drivers. The home indoor environment, such as air quality, ventilation, and thermal/visual comfort, directly influences the quality of life, health, and productivity (Mujan et al., 2019). The tradeoffs and correlations between the aforementioned factors and home energy consumption patterns can provide insight for incorporating human dimensions in energy policy and planning, particularly in DR programs, building control, and energy pricing. Respondents were first asked about their expectations and perception about home thermal conditions in terms of temperature and humidity and the extent $(1-10)$ to which thermal comfort impacts their quality of life (Fig. 8). The results demonstrate that although indoor comfort is perceived as a significant factor in quality of life, thermal comfort satisfaction is not fully provided. This discomfort can result in overusing air conditioning systems and adjusting thermostat setpoints or device operation to noneconomic settings, regardless of the adverse impact on the user's well-being. The focus was then shifted toward the association between thermal comfort and financial drivers, and respondents were asked about their average monthly electricity bill and whether their bills were included in their rent or whether they benefited from energy subsidies. As seen in Fig. 9, average monthly electricity bills follow a right-skewed distribution, and $52.9 \%$ of the survey participants are exempted from paying electricity bills. This information is analyzed later in this article to evaluate whether energy subsidies and included bills impact consumption behavior.

To understand the impact of financial drivers on energy consumption and evaluate the willingness to participate in residential DR programs, including remote air conditioning and major appliance control, participants were asked about four main concerns as illustrated in Fig. 10. First, to assess any association between financial concerns and consumption habits, respondents were asked if electricity prices could influence their consumption. 


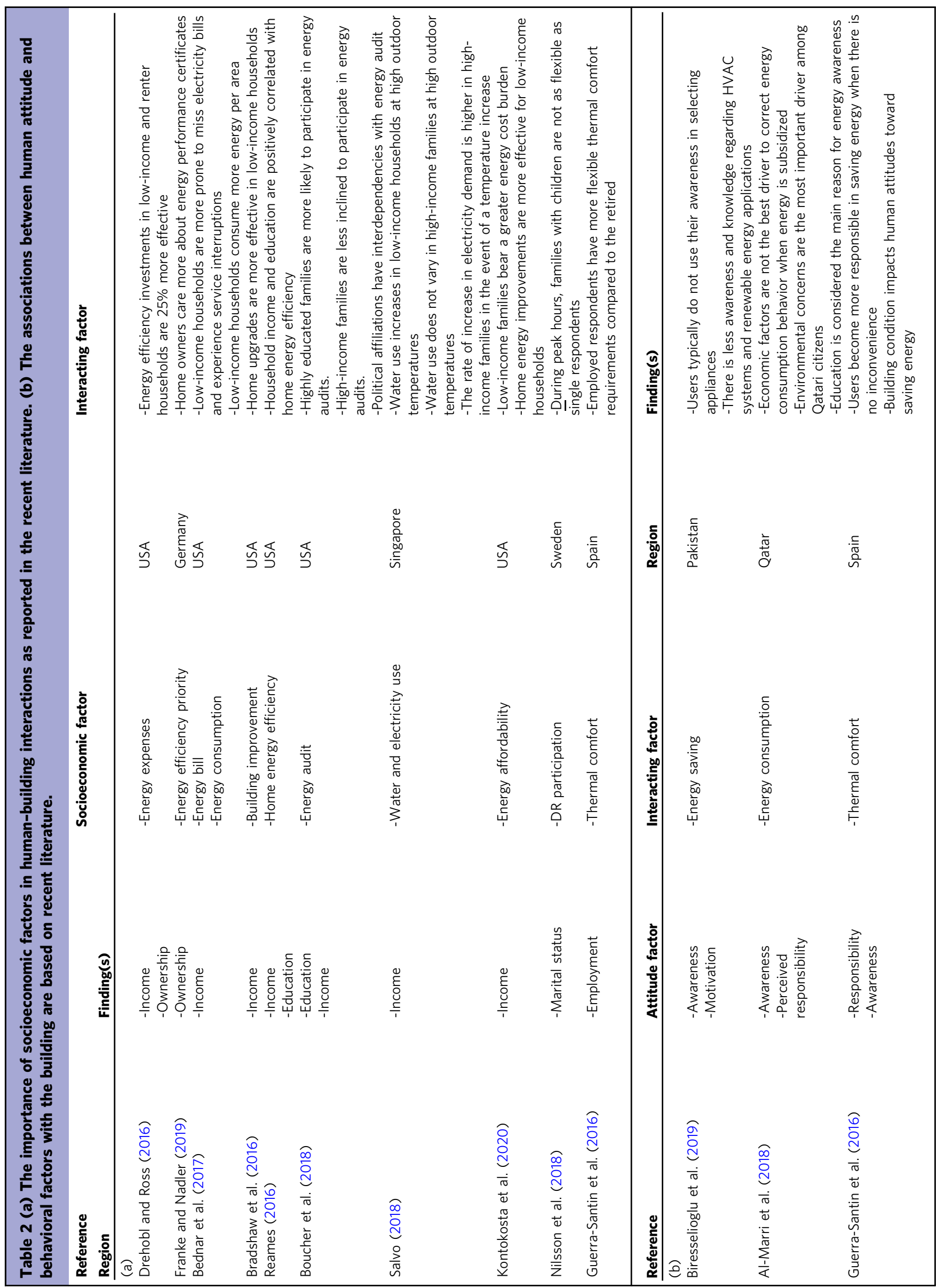




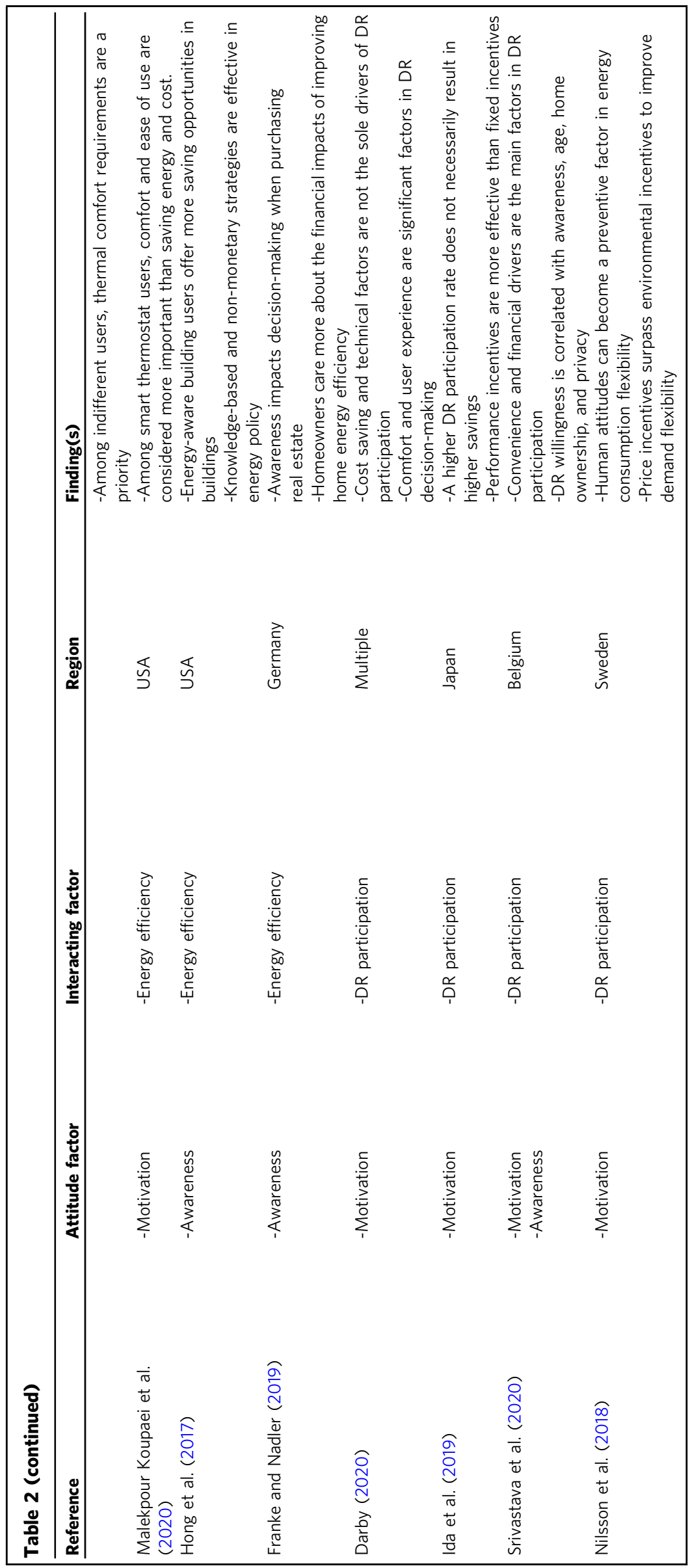



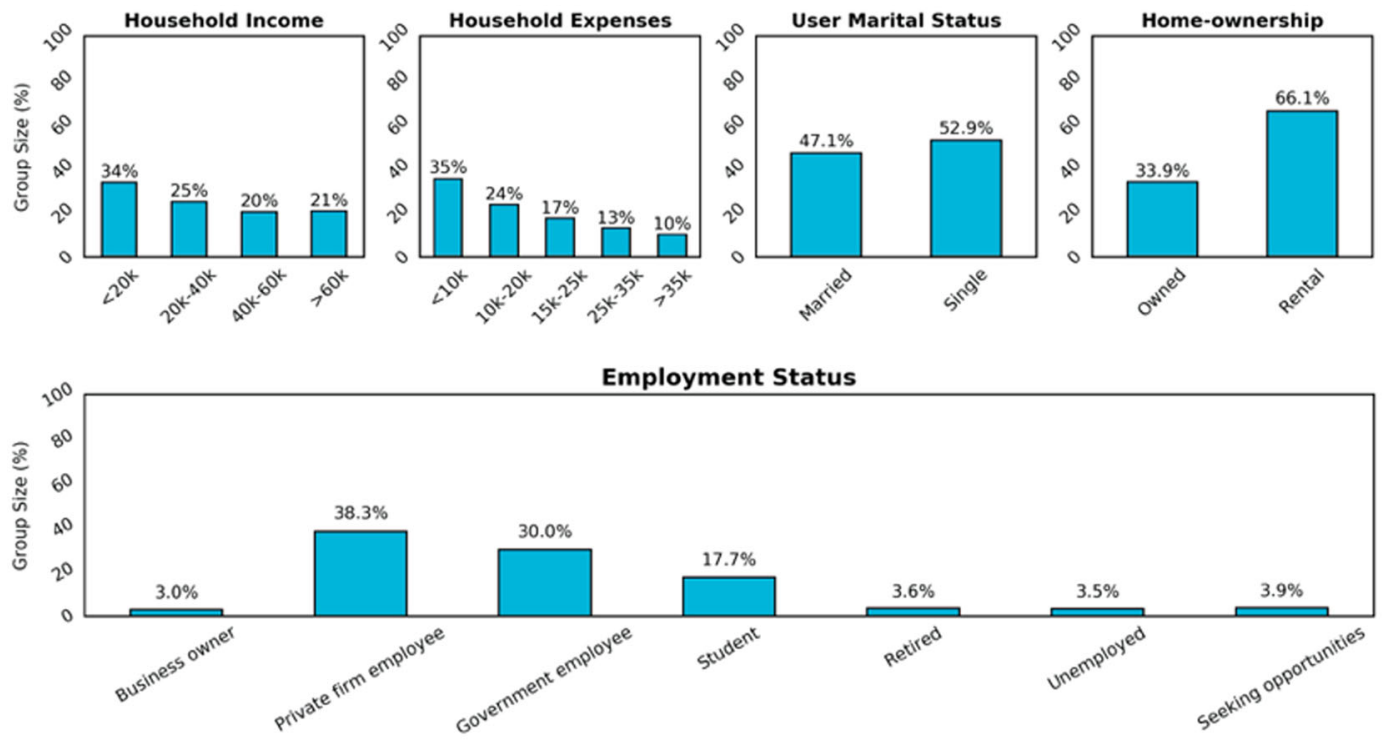

Fig. 5 The distribution of the socioeconomic factors in the survey. The distribution of the sample's demographic factors.

This insight can offer useful information to decision-makers in terms of choosing to rely more on pricing schemes or targeting other factors, such as awareness, energy efficiency incentives, and interventions to curtail energy consumption. Second, participants were asked about the impact of not paying utility bills on their consumption habits. This issue is crucial in a country such as Qatar and the GCC union with an increasing rate of new rental apartments with offers and promotions associated with free utility bills. Such strategies might be attractive to business owners but can impose a burden on the power grid due to unnecessary overconsumption by the tenant. This fact is verified by the data because, nearly half of the sample reported that free utility bills could increase their consumption habits, or they are unsure about the possible outcome. Third, regarding the willingness to participate in residential DR programs, $46.4 \%$ were against such programs. This information is important because the major barriers to adopting DR strategies must be investigated through social and psychological analysis. For instance, if the main concern is inconveniences, decision-makers must ensure reliable and convenient building operations. If financial incentives can motivate the user to participate, the problem requires a detailed economic analysis to customize incentives based on factors such as building size, energy saving margins, and accessibility. Thus, in the fourth question, users were asked about the type of possible financial incentives that might convince them to participate. The results showed that $34.6 \%$ of the sample accepted the offer if they received a portion of their monthly bill, $16.2 \%$ accepted the offer if an additional credit was paid on top of the amount of their monthly bill, and the remainder were declined any financial offer. Figure 11 illustrates that an offer of $\sim 20 \%$ of the monthly bill or $500 \mathrm{QR}$ on top of the waived utility bill seems to be an attractive incentive for most users.

Human-building interaction in workplaces. The other goal of this study was to understand human-building interactions at workplaces. This investigation is important because human factors can disrupt proper and efficient building operations, including opening windows and overriding thermostat settings. Such interactions might be caused by thermal/visual discomfort or adverse prior habitual norms. Moreover, in commercial buildings and office spaces, human performance and productivity are priorities; thus, the building operator must ensure the tradeoff between indoor thermal comfort and saving energy. First, respondents were asked about their workplace characteristics, such as construction year, workplace type, and whether their workplace could be considered a technologically advanced environment (Fig. 12). The results indicate that most of the respondents' workplaces were built after the 2000s. Furthermore, $\sim 66 \%$ of the respondents work in office spaces (closed personal/ shared, cubicle, open offices), and $72.6 \%$ of the users believe that their workplaces are technologically advanced.

The next set of questions was designed to target human-building interactions and user preferences regarding thermal/lighting comfort (Fig. 13), along with their perception and the impact of indoor environment comfort level on their productivity at work (Fig. 14). As seen in Fig. 13, not all respondents can adjust the thermostat to their preferred operating temperature level or open windows, but if they can, the likelihood of adverse interruptions is nearly half the likelihood if the user does not override the thermostat setpoint or open windows. A small proportion of respondents (11.3\%) preferred indoor temperatures above $24^{\circ} \mathrm{C}$, whereas the majority $(45.3 \%)$ preferred temperatures below $22^{\circ} \mathrm{C}$, which increased cooling demand. Furthermore, indoor lighting preference is noticeably dominated by moderate lighting. According to Fig. 14, although the reported impact of indoor environmental conditions on human productivity is more inclined toward a very important factor, this tendency does not match the perceived indoor environment at work. This finding is important because whether their $\sim 65 \%$ of respondents believe that a better workplace environment improves their productivity, whereas $25 \%$ do not perceive any impact.

\section{Categorization of energy consumers}

A crucial insight that can support energy policy decisions is the identification of the main human-driven factors that influence consumption habits and patterns. This insight can help decisionmakers target different segments in society based on demographic and socioeconomic factors to develop strategies concerning actions, such as awareness improvement, incentive modeling, interventions, pricing, and coercive actions. This insight is particularly important for GCC countries with a wide range of human-oriented characteristics. 

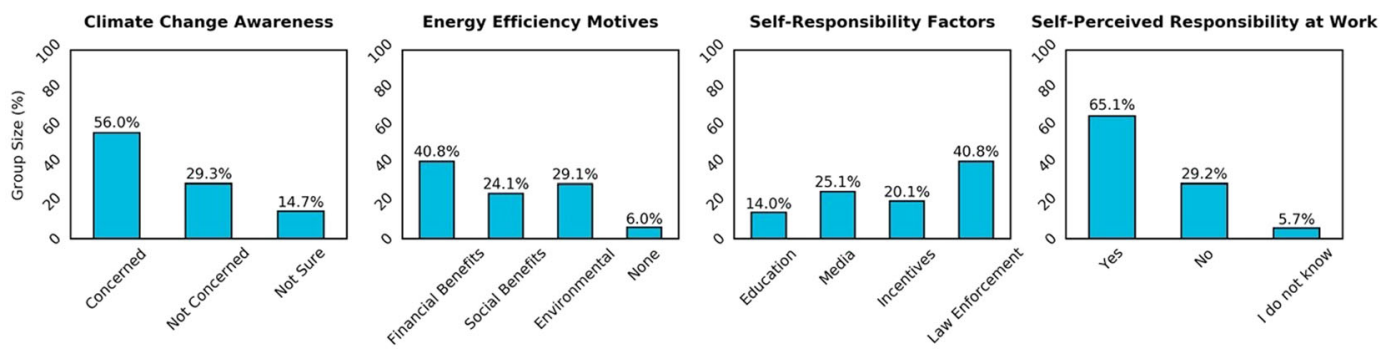

Fig. 6 The distribution of the responses involving human attitudes and behavioral factors. Respondents were asked about awareness of climate change consequence awareness, motivations towards for improving home energy efficiency, opinion about the most important factor improving energy responsibility, and self-perceived responsibility at work.

Consumer clustering. To determine a measure to compare consumption patterns, the average monthly electricity payments in Fig. 9 were divided by floor area (Fig. 7) to calculate a new attribute equivalent to EUI. This conversion is reliable because Qatar's residential rate structure is not based on dynamic pricing schemes. Next, we used the $k$-means clustering method (Jin and Han, 2010) to partition EUI values into two different consumption patterns, namely, low and high consumers. This method partitioned 1021 respondents, with no missing data in the sample, into 829 category 1 users with a centroid of EUI $=2.89 \frac{\mathrm{QR}}{\mathrm{m}^{2}}$ representing low consumers and 192 category 2 users representing high consumers. The EUI values are sorted and highlighted for the two patterns in Figs. 15 and 16. These two patterns are used to conduct a feature importance analysis.

Feature importance analysis. Random forest classifiers are among the ensemble methods that use bootstrap aggregating (bagging) to sample the training dataset to construct a set of decision tree estimators (Breiman, 1996). The objective of the bagging method is to construct an ensemble of predictors with respect to random subsets of the main training dataset to improve the generalization of the ensemble. Decision trees can fit intricate patterns for both classification and regression tasks. There are several decision tree learning algorithms that, in general, have the objective of recursively splitting samples into homogenous subsets (nodes) based on an attribute.

The trained classifier enables conducting feature importance analysis. To achieve this goal, we use three specific techniques:

- Gini impurity:

The measure of the quality of split is based on metrics such as the Gini impurity, defined as

$$
G_{i}=1-\sum_{k=1}^{n} p_{i, k}^{2}
$$

where $G_{i}$ is the Gini impurity of node $\mathrm{I}$, and $p_{i, k}$ is the ratio of class $k$ among all instances in node $i$. The cost function to train a decision tree based on the Gini impurity and the CART algorithm to find the optimum split is defined as follows (Breiman, 1984):

$$
J\left(k, t_{k}\right)=\frac{m_{\text {left }}}{m} G_{\text {left }}+\frac{m_{\text {right }}}{m} G_{\text {right }}
$$

where $J\left(k, t_{k}\right)$ is the cost function based on feature $k$, threshold $t_{k}, G_{\text {left/right }}$ is the impurity of the left or right subset, and $m_{\text {left/right }}$ is the number of instances on the left or right. In a random forest classifier, random sampling is applied to both the training dataset and the feature set. An inherent feature of random forest classifiers is their capability to measure the relative importance of features.
The feature importance is determined based on the extent to which a feature, on average, reduces the impurity measure based on Eq. (4).

$$
\begin{gathered}
\mathrm{NI}_{i}=w_{i} G_{i}-w_{\text {right }, i} G_{\text {right }, i}-w_{\text {left }, i} G_{\text {left }, i} \\
\mathrm{FI}_{i}=\frac{\sum_{j \text { :node } j \text { splits on feature } i} \mathrm{NI}_{j}}{\sum_{j \in \text { all nodes }} \mathrm{NI}_{j}}
\end{gathered}
$$

where $\mathrm{NI}_{i}$ is the importance of node $i, w$ is the weighted number of instances, and $\mathrm{FI}_{i}$ is the importance of feature I.

- Permutation importance: measures the increase in the prediction error of the model after permuting the feature's values, which breaks the relationship between the feature and the true outcome. A feature is deemed important if shuffling its values increases the model error because in this case, the model relies on the feature for the prediction. A feature is deemed unimportant if shuffling its values leaves the model error unchanged, as in this case, the model ignores the feature to make the prediction.

- SHAP: The SHAP explanation method calculates Shapley values from coalitional game theory. The Shapley value is a solution concept in cooperative game theory (named for Lloyd Shapley, who introduced it in 1951 and won the Nobel Prize in Economics for it in 2012). The feature values of a data instance serve as players in a coalition. Shapley values reflect how to fairly distribute the payout (i.e., the prediction) among the features. A player can also be a group of feature values. For example, to explain an image, pixels can be grouped into superpixels, and the prediction is distributed among them. One innovation of SHAP is that the Shapley value explanation is represented as an additive feature attribution method.

Two random forest classifiers were constructed to measure the relative importance of demographic, socioeconomic, and behavioral factors with respect to the consumption pattern demonstrated in the previous section as the target variable. The random forest was an ensemble of 500 decision tree classifiers trained via the bootstrap algorithm, random patches method, and Gini impurity. The first model was based on five attributes, age range, gender, ethnicity group, household income, and monthly expenses, as the independent variables to classify the consumption category (high consumer and low consumer). Based on a 10 -fold cross-validation analysis, the random forest estimators are capable of classifying the two classes with an average accuracy of $93.5 \%$, ranging from $90 \%$ to $97.1 \%$. Due to the random behavior of the feature importance procedure, the analysis was conducted for 1000 iterations to compute the average feature importance of the independent attributes. 

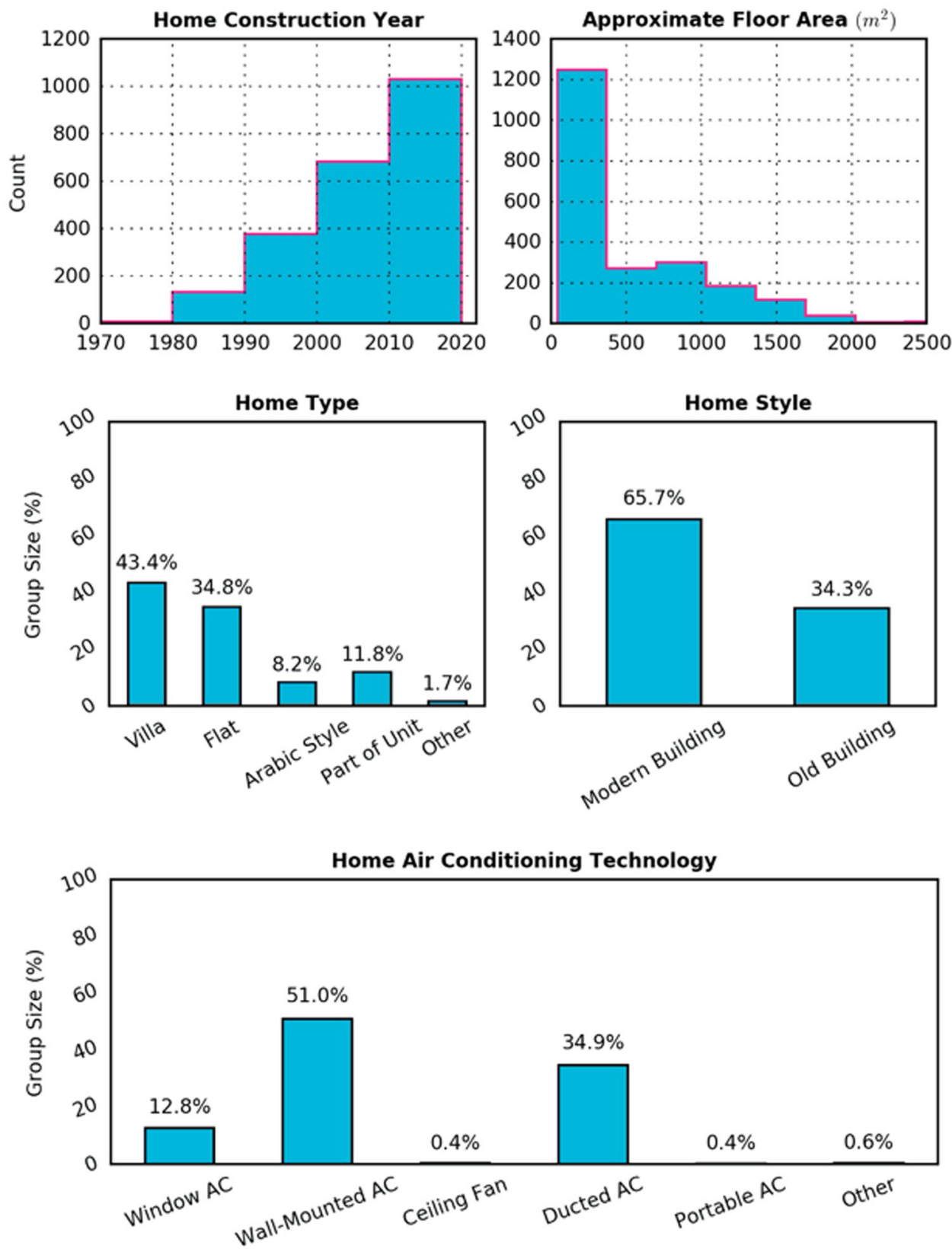

Fig. 7 The characteristics of respondents' dwellings.

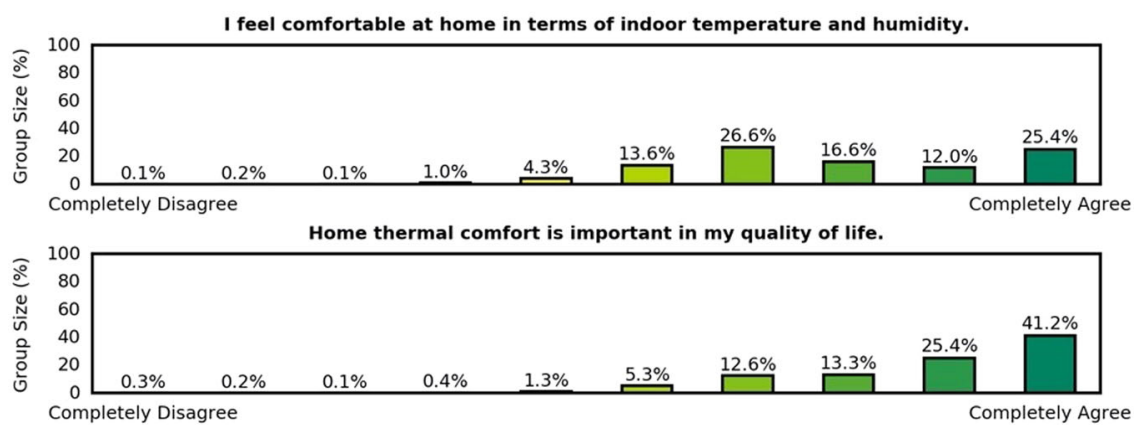

Fig. 8 Information on self-perceived indoor comfort at home and how home thermal comfort influences respondents' quality of life. 

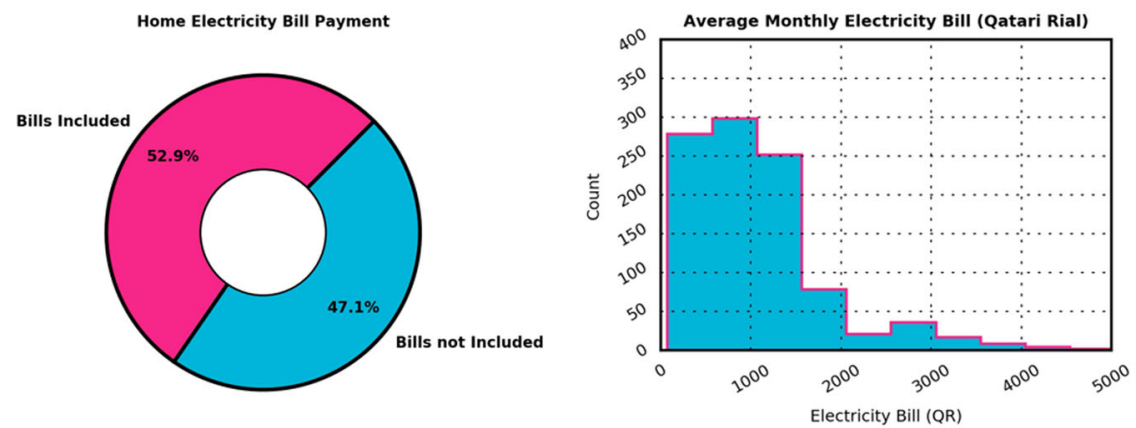

Fig. 9 Electricity bill payments and financial factors that can be attributed to respondents' consumption behavior.

(a)

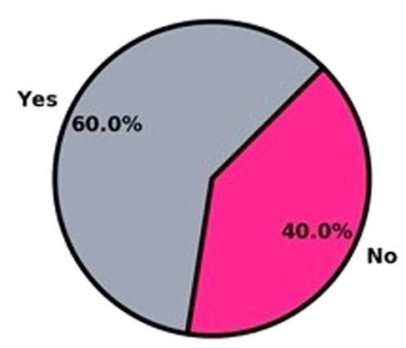

(c)

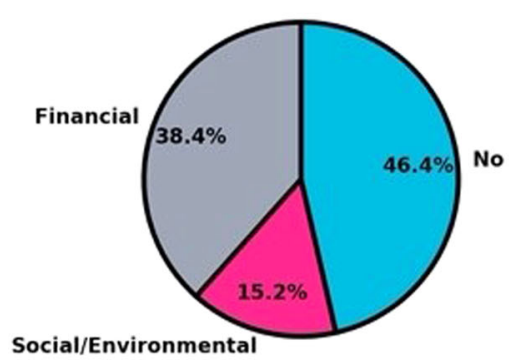

(b)

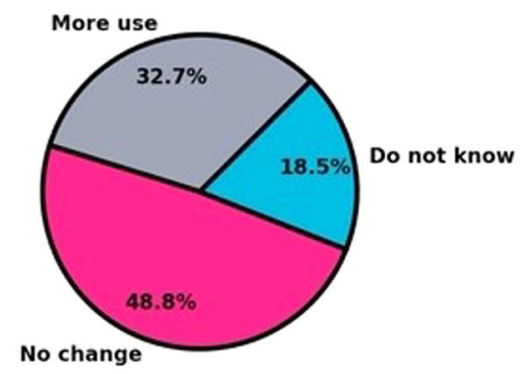

(d)

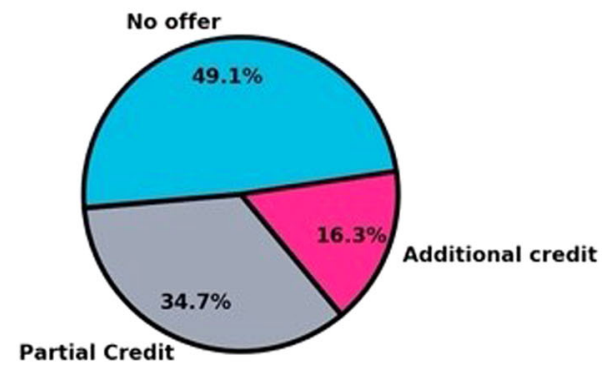

Fig. 10 Impact of financial drivers on energy consumption. Participants' response to the following questions: a Can a high electricity bill be a factor in your decision to consume less energy at home? $\mathbf{b}$ If you don't have to pay utility bills, how would your electricity and water consumption be impacted? $\mathbf{c}$ Are you willing to allow an entity to remotely control your AC or major appliances, given that the operation is safe and reliable? and $\mathbf{d}$ What offer would you accept to let a company remotely control your AC or major appliances?.

The same procedure was also conducted based on another independent variable set: consequence awareness, motives for adopting home energy efficiency, and the perceived factors that improve self-responsibility. The second classifier has an average accuracy of $92.6 \%$, ranging from $90 \%$ to $95.1 \%$ for 10 -fold crossvalidation. Notably, these three variables are correlated with the independent variables in the first random forest classifier. The results are shown in Figs. 17-19, where the feature importance order is household expenses, age, ethnicity, gender, and income for the first classifier and responsibility factor, energy efficiency motives, and awareness for the second classifier. The order of the feature importance array resulting from three calculation techniques indicates that household expenses, respondent age, and ethnicity group provide adequate information to differentiate household energy consumption patterns. In addition, an individual's awareness of consequences does not necessarily impact the energy consumption category. These conclusions mainly demonstrate that household monthly expenses better represent the energy consumption patterns of a family than income level. There seems to be other information embedded in the household monthly expenses level, such as building characteristics, appliance types, and appliance use. Intuitively, the user's gender cannot be attributed to the aggregate behavior of a household. Furthermore, the respondent's age and ethnicity group can represent the household's energy behavior. With respect to behavioral factors, the findings depicted in Figs. 20-22 show that a family member's consequence awareness does not create a positive or negative effect on aggregate household energy patterns.

Figure 23 shows the associations between energy consumption categories and the aforementioned variables. Based on this figure, high consumption patterns are more likely to be observed in older age groups, and North American and Arab ethnicity groups show high consumption habits. Furthermore, respondents with financial concerns about home energy efficiency along with the groups motivated by financial incentives were among the highest consumers. Notably, although obvious visualized patterns might suggest correlations 

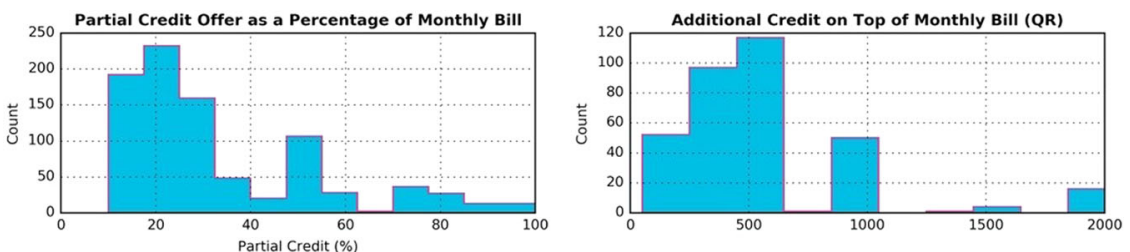

Fig. 11 Participants' preferred incentive to join a DR program. Two types of offers to incentivize a customer to participate in a DR program, including partial credit based on their monthly bill or additional credit on top of their monthly bill.

Workplace Condition

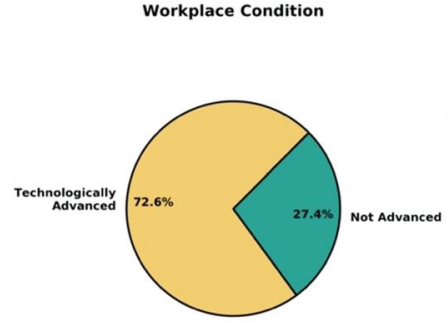

Workplace Construction Year

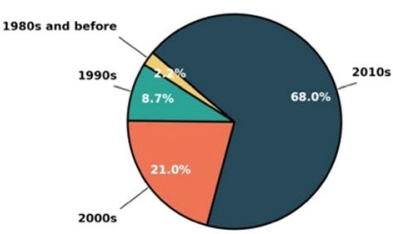

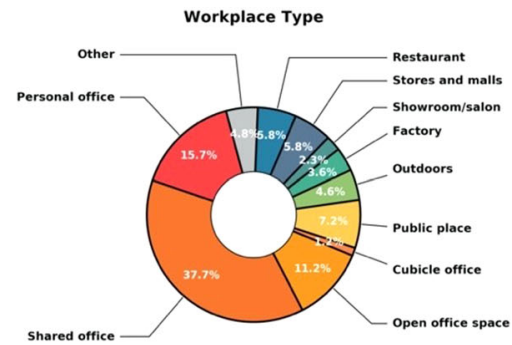

Fig. 12 Additional information on respondents' workplace characteristics.

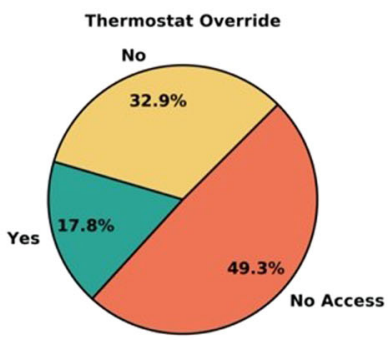

Preferred indoor temperature

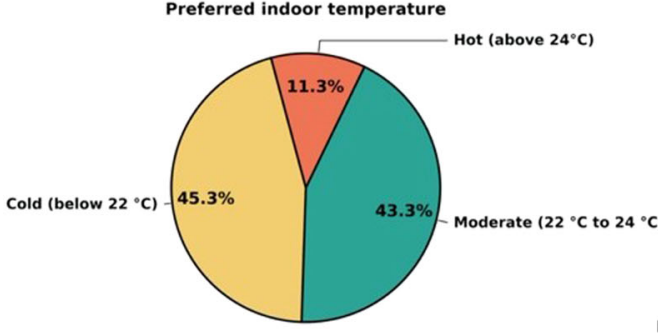

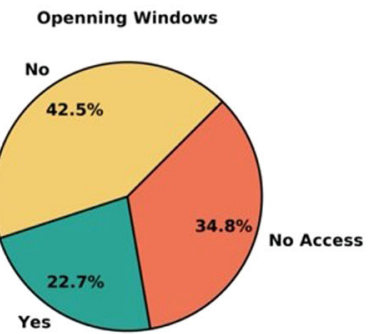

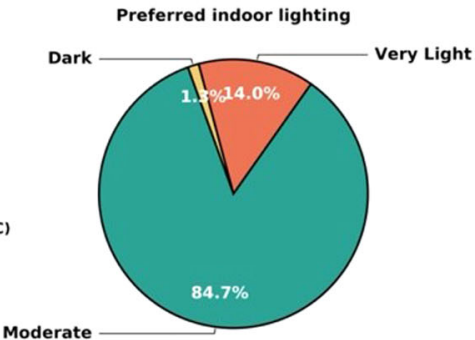

Fig. 13 Participants' perceived interactions with the building along with their preferred work environment.

with energy consumption categories, we must consider the feature importance algorithm, in which a sequence of traits specifies the class, not a single feature.

\section{Discussion}

In this section, we further analyze and explain the associations between the factors that represent four major concerns: (1) human-building interactions and thermal comfort in residential buildings, (2) human-building interactions in workplaces and productivity, (3) energy attitudes and behavioral factors, and (4) financial drivers in residential buildings.

Analysis of thermal comfort in residential buildings. Additionally, the main objective of heating, ventilation, and air conditioning (HVAC) systems is to maintain the indoor environment within the comfort zone. As demonstrated, HVAC load accounts for a large proportion of the total energy consumption of buildings, particularly in hot climates. The cooling demand is a flexible end-use with a high potential to curb the electricity demand, given that a pleasant indoor environment is still provided based on the user's preference. Although saving energy is critical, its potential impact on the comfort zone must not be neglected because it directly influences the occupant's well-being. It is well established that such impacts and human preferences are correlated with demographic and socioeconomic factors (e.g., Schweiker et al., 2018; Sintov et al., 2019). Figure 24 shows violin plots based on KDE distributions of the respondents' perceptions about thermal comfort at home and the importance of the comfort level for their well-being. The left column in Fig. 24 shows users' perceptions of comfort level, whereas the right column shows the importance of indoor thermal comfort for their well-being based on gender, income, and ethnicity. In general, the comfort level for females is more concentrated around higher scales, implying that women experience more comfort at home than men. The gender-based categorization in the right column also shows that indoor comfort is more important to women. The categorization based on the household income level 


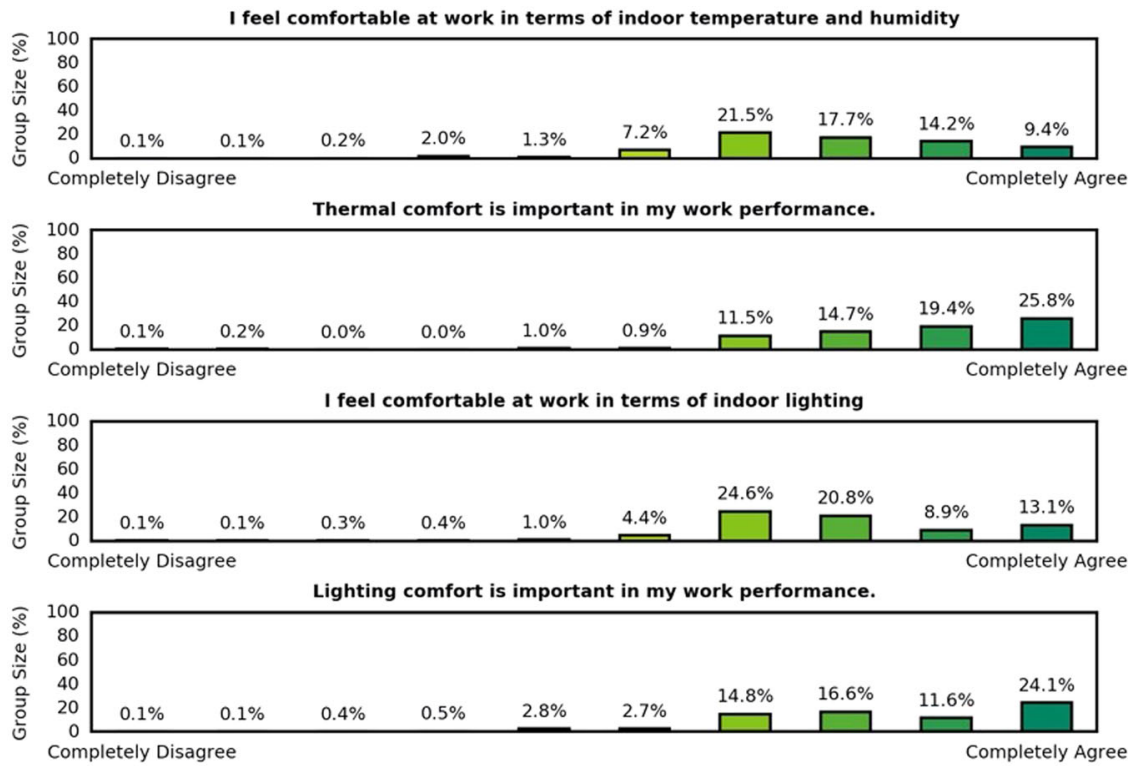

Fig. 14 Participants' clarification of their perceptions of the work environment and its impact on their performance.

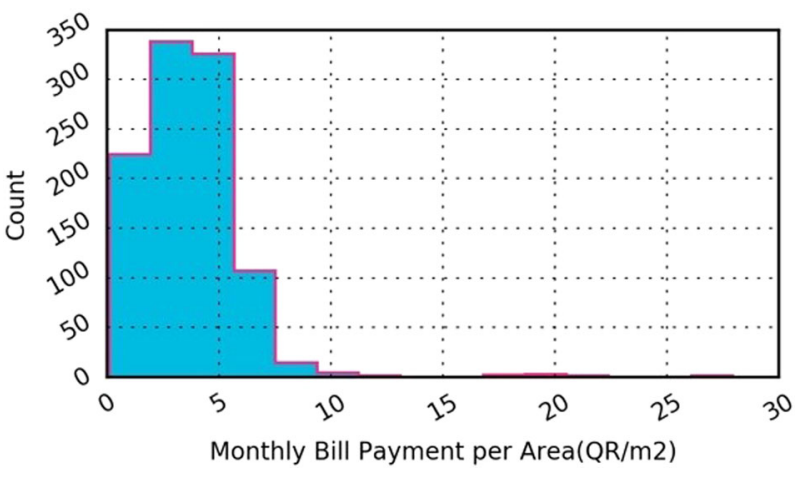

Fig. 15 The distribution of users' energy use intensity based on their average monthly bill payments and home floor area.

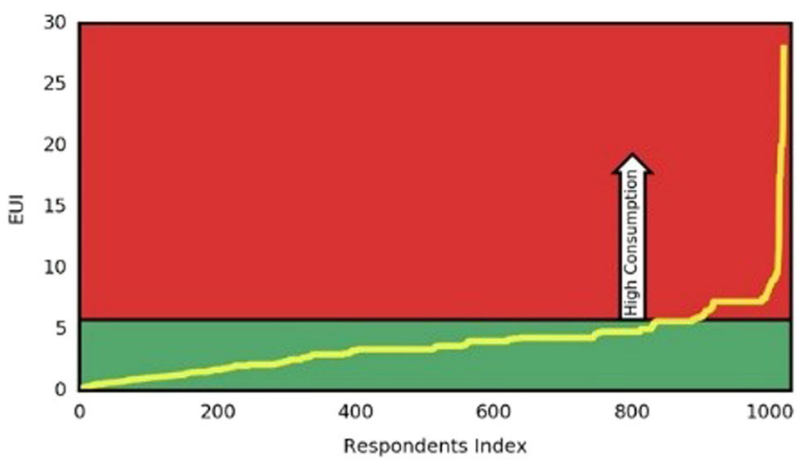

Fig. 16 Grouping participants by normalized monthly bill per area.

Clustering the participants into low (green area) and high consumer (red area) categories based their normalized monthly bill per area using the $k$ means clustering algorithm.

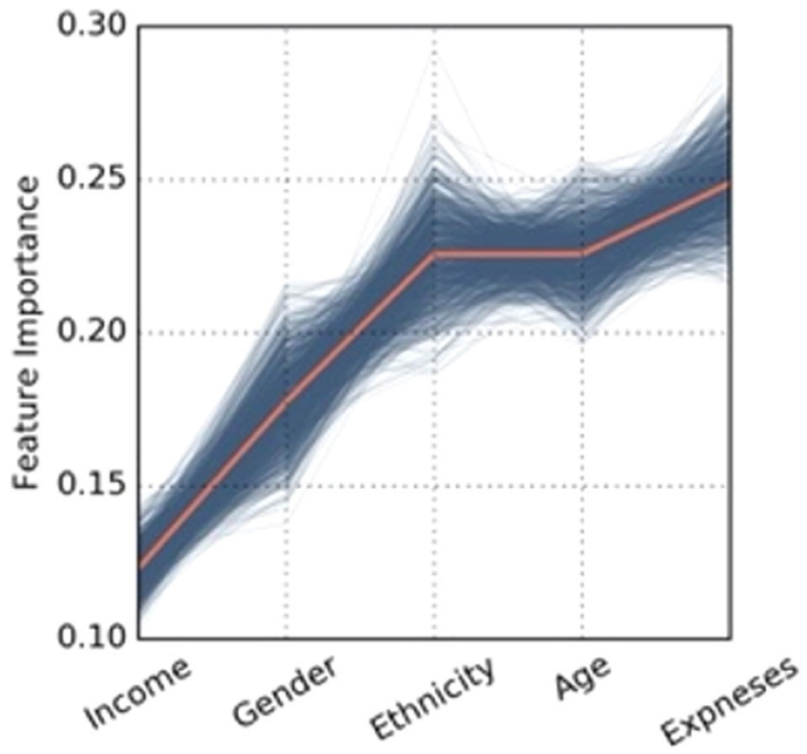

Fig. 17 Feature importance analysis of the energy consumer categories based on demographic and socioeconomic factors using the Gini impurity.

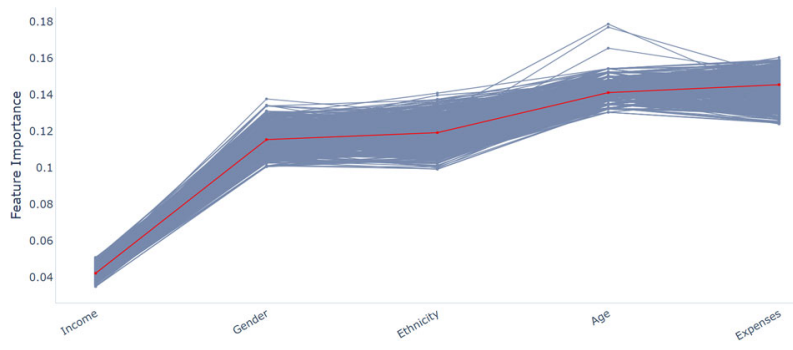

Fig. 18 Feature importance analysis of the energy consumer categories based on demographic and socioeconomic factors using permutation importance. 


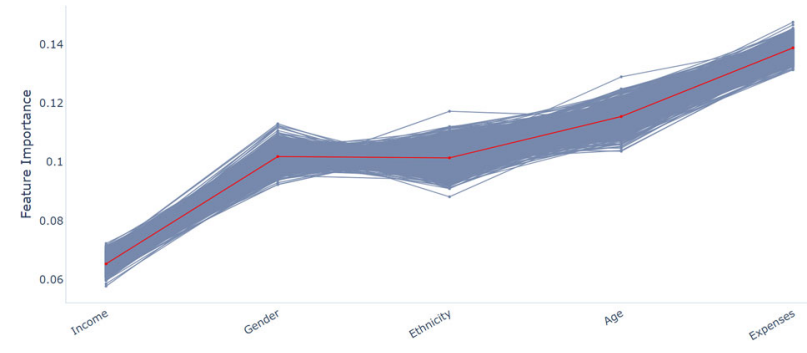

Fig. 19 Feature importance analysis of the energy consumer categories based on demographic and socioeconomic factors using SHAP.

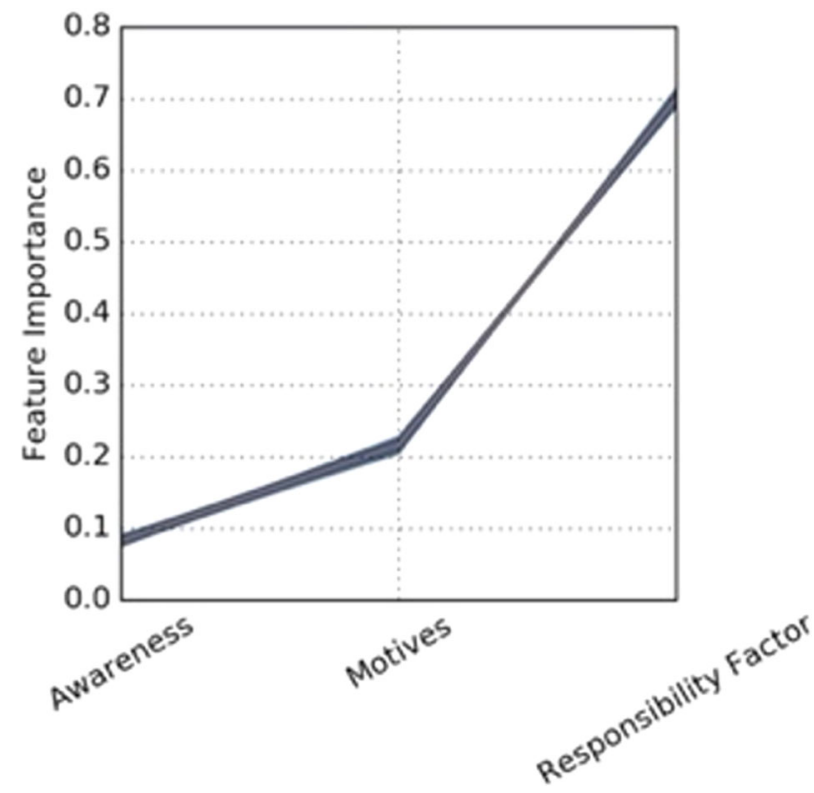

Fig. 20 Feature importance analysis of the energy consumer categories based on human attitudes and behavioral factors using the Gini impurity.

demonstrates positive correlations with the respondent's perceived comfort and comfort importance. Finally, the comfort levels differ based on the ethnic group; Qataris, Europeans, and Arab nationalities attach greater importance to indoor comfort than North American, Asian, and Indian ethnic groups. This insight can help develop strategies in electricity pricing and financial incentive modeling to improve the well-being of communities. It can also be used to quantify penalty factors for comfort deviation and building design, operation, and control guidelines.

There are correlations between the occupant's comfort level and building construction type and conditions. According to Fig. 25, excluding the buildings constructed in the 1970s and 1980 s, there is an overall improvement in the indoor comfort level for newer constructions. In addition, there is greater indoor environment satisfaction in villas and Arabic-style homes compared to flats and part of unit residential types. Furthermore, modern buildings provide more comfortable indoor environments. Finally, a comparison between different types of air conditioning systems revealed that central ducted systems and wall-mounted units offer more indoor comfort than window air conditioners and ceiling fans. In summary, when investigating human-building interactions in residential systems, correlations between human comfort and the aforementioned factors should be comprehensively analyzed. For instance, some energy efficiency and retrofit financial incentives can be prioritized and

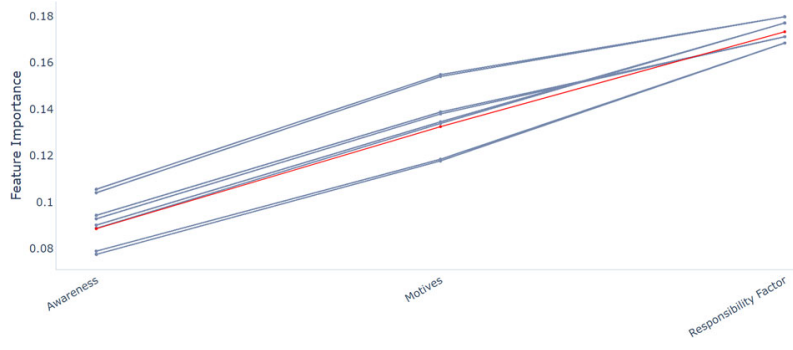

Fig. 21 Feature importance analysis of the energy consumer categories based on human attitudes and behavioral factors using permutation importance.

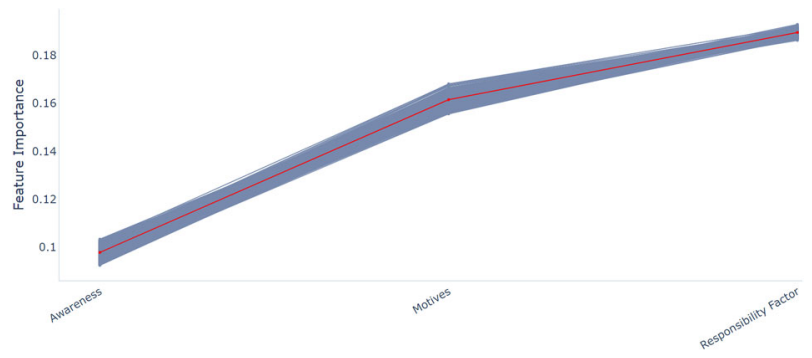

Fig. 22 Feature importance analysis of the energy consumer categories based on human attitude and behavioral factors using SHAP.

directed toward systems providing the lowest comfort levels (and least efficiency) to improve the overall well-being of society and energy efficiency indicators simultaneously.

Analysis of thermal comfort in workplaces. The impact of the quality of the indoor visual and thermal environment in workplaces not only influences human well-being but also introduces financial challenges if lacking. A comfortable indoor environment improves human productivity and performance (Seppänen et al., 2006) and, in turn, the overall performance indicators of businesses. Furthermore, thermal and visual comfort measures can be customized to capture lower consumption modes and thus users' preferences for possible energy saving opportunities. Figure 26 shows that perceived comfort in the indoor environment in workplaces varies depending on gender and ethnic group. Female respondents tend to favor colder temperatures (below $22^{\circ} \mathrm{C}$ ), whereas males are more inclined toward moderate indoor temperatures $\left(22-24^{\circ} \mathrm{C}\right)$. In terms of ethnicity, Arab nationalities and North Americans favor cold environments, whereas Asians prefer hot indoor environments. Concerning preferred lighting systems, the only significant pattern observed was that Asian ethnic groups prefer light workplaces. Figure 27 presents patterns concerning human-building interactions. The results indicate that female respondent's show are less inclined to override the thermostat or open windows, whereas Asians are more likely to open windows or change thermostat settings at work.

Furthermore, patterns shown in Fig. 28 were identified regarding the respondents' perceived comfort at work and how the comfort level impacts their work performance and productivity. Similar to the perceived comfort at home, for female respondents, thermal comfort impacts their work performance more than it does for male respondents. A positive correlation between income and both perceived comfort at work and influence on productivity was also observed. Concerning ethnic groups, Indians and Asians experience less comfort, though thermal comfort is a less significant factor for their productivity. Figure 29 shows the correlations between indoor environment 


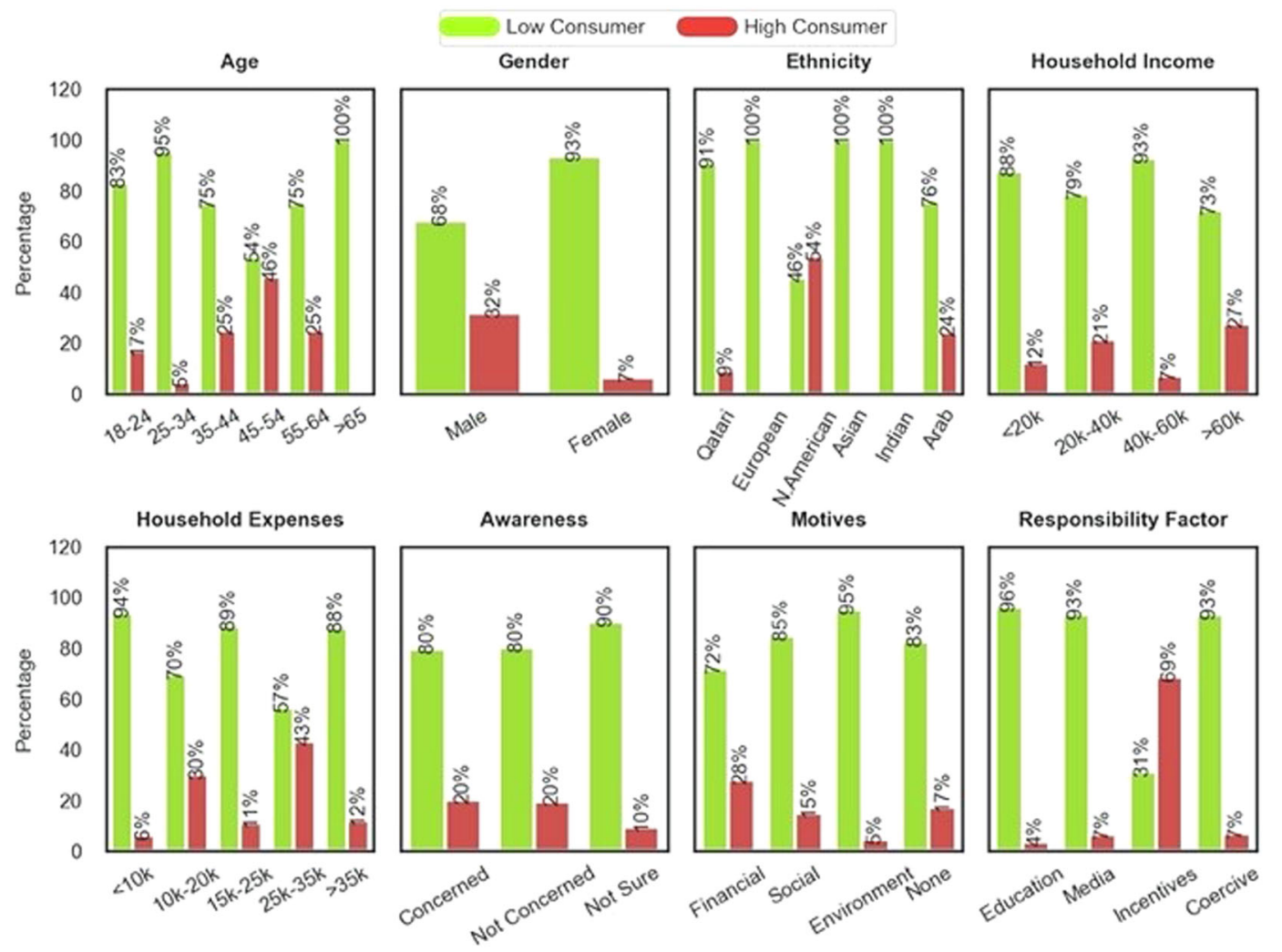

Fig. 23 Energy consumer categories demonstrated based on human-oriented factors.
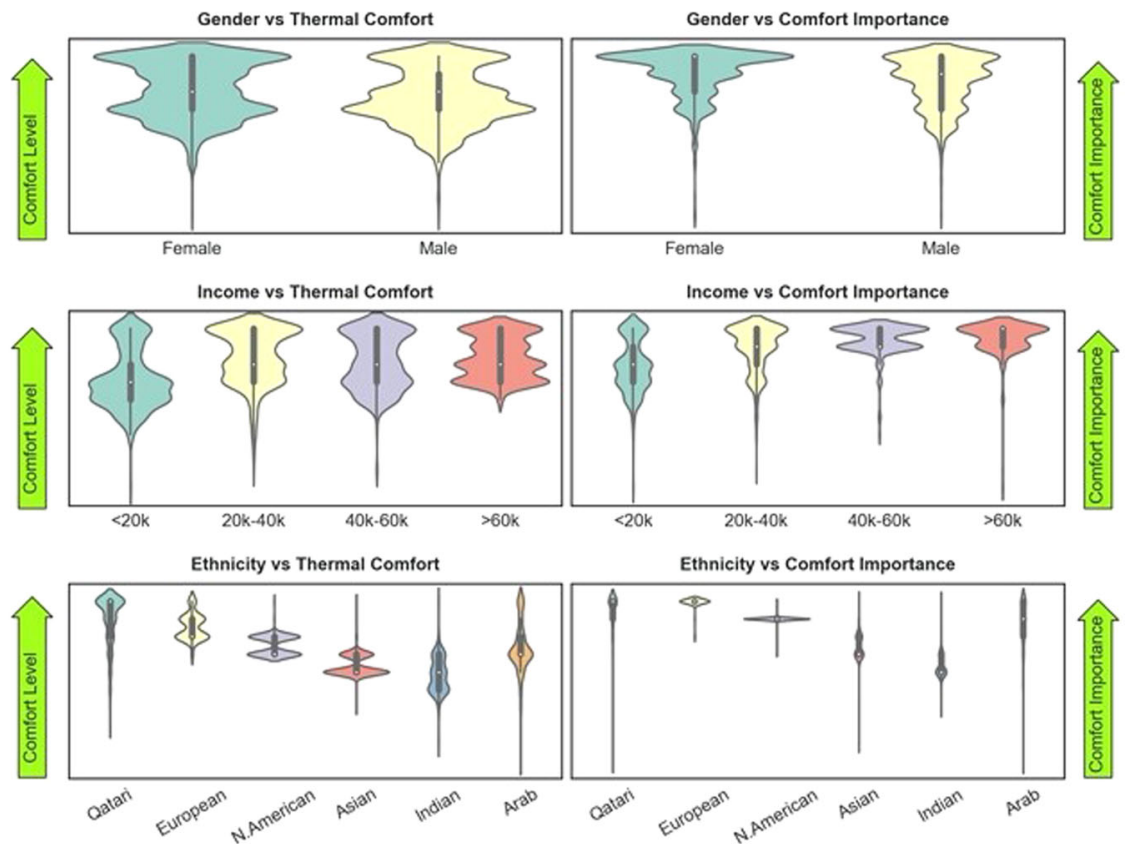

Fig. 24 Users' perceptions of comfort level. Associations between demographic factors and participants' perceived thermal comfort at home (left column plots) and indoor comfort importance for the respondents' quality of life (right column plots) based on Kernel density estimation.

preference and human-building interactions with perceived comfort level at work. The results indicate that those with hotter indoor environment preferences experience greater discomfort. In addition, thermal discomfort level is more common among respondents who typically override the thermostat and open windows. This pattern indicates the significance of thermal comfort in avoiding adverse human interruptions. Figure 30 also shows the impact of building construction and attributes on the perceived comfort level. A noteworthy finding is that people working in open office spaces experience greater discomfort, 

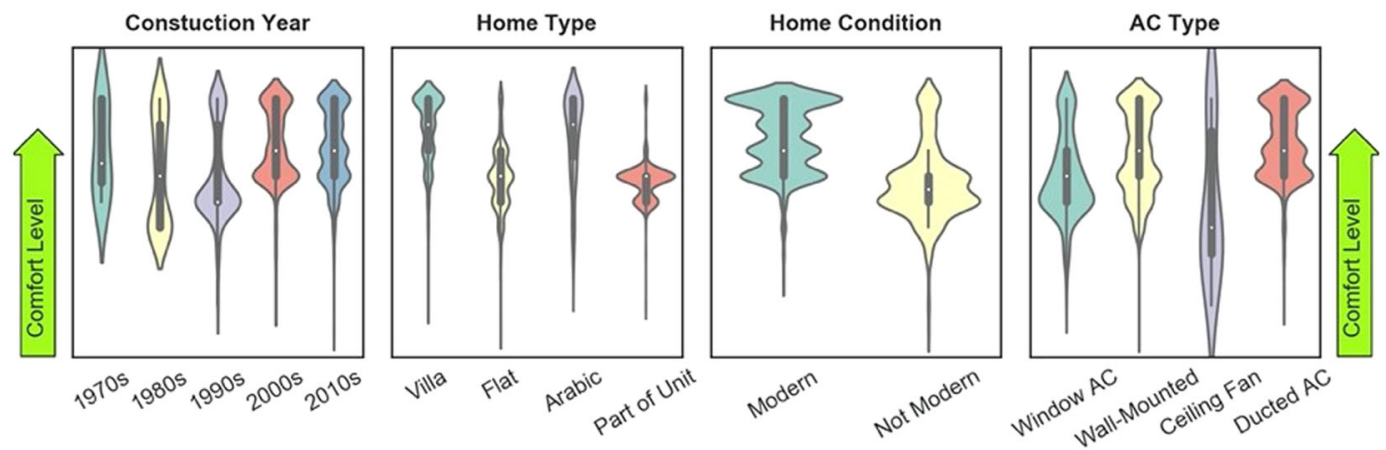

Fig. 25 Correlation between perceived thermal comfort at home and dwelling characteristics.
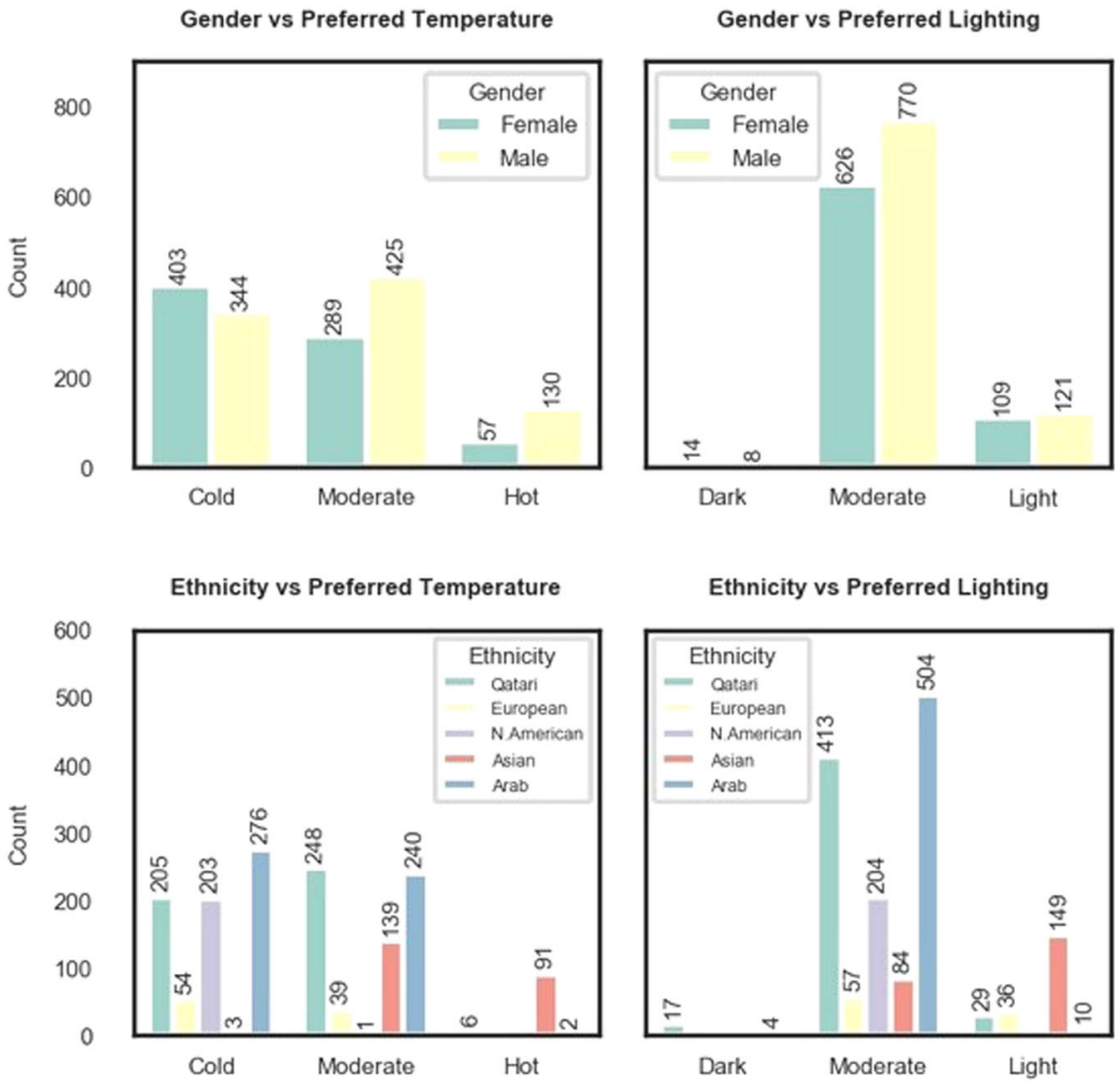

Fig. 26 Intercorrelations between the demographic factors and users' preferences in the workplace indoor environment.

whereas personal office users have a higher perceived comfort level at work.

Awareness, motives, and responsibility. The associations between human dimensions and factors regarding the awareness of climate change consequences, motives for home energy efficiency, perceived factors that can improve energy consumption responsibility, and perceived energy consumption responsibly at work are assessed in this section. This insight can help decision-makers reshape strategies (e.g., raising awareness and establishing personal/social norms) to target population segments more purposefully. In Fig. 31, the first-row plots show how the consequence awareness factor is associated with gender, income, and ethnic group. According to the results, female respondents are more concerned about climate change, there is less concern among Arab and Indian ethnic groups, and considering income, the highest income group is the most concerned. In Fig. 31, the second-row plots show that financial motives for home energy efficiency are more important for male respondents; Qataris' main motivation regarding home energy efficiency is social and environmental, whereas financial factors are the main driver for other ethnic groups, and financial motives are more critical for lower-income groups. The third-row plots show that coercive factors are perceived as more effective among male respondents. Considering ethnicity, education is important among European respondents, financial incentives are more dominant among North Americans and coercive actions among other ethnicities. As shown in the fourth-row plots, considering self-perceived energy responsibility at work, female respondents exhibit significantly more responsible behavior. This self-perceived responsibility is lower in Asian and Indian groups but evokes mainly a positive response among other ethnic groups. Finally, the lowest-income group shows the highest proportion of adverse interactions in work environments. 

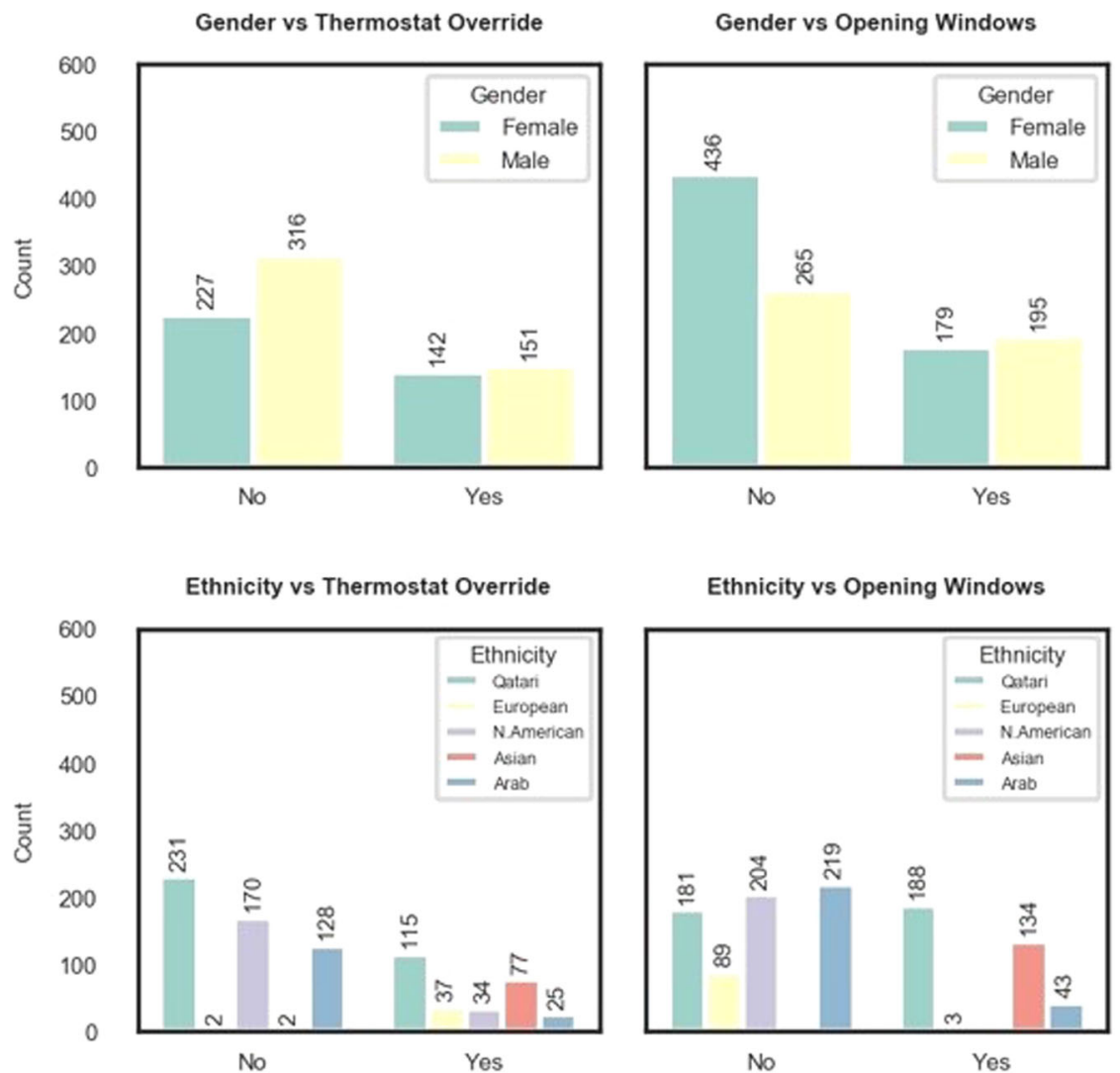

Fig. 27 Intercorrelations between the demographic factors and users' interactions with the building.

Financial drivers in energy consumption patterns. Identifying the main financial drivers of home energy consumption patterns and their associations with human-driven factors can provide insights to support the development of energy strategies. For instance, it should be determined whether high electricity prices of energy subsidies change human energy consumption behavior. Figure 32 shows how gender, ethnicity, and income influence energy pricing and energy use associations. The results indicate that high electricity prices can be a major factor for male respondents in changing their energy consumption. This finding is also more common among Arab, Asian, and Indian ethnic groups. Furthermore, among low-income respondents, high electricity prices can reduce consumption, whereas, among the high-income group, electricity pricing is less effective. Figure 32 (second row) also illustrates the relationship between willingness to participate in DR and human factors. The results indicate that male respondents are more willing to participate in DR programs for financial reasons, whereas for female respondents willing to participate in DR programs, social/environmental incentives are comparable to financial incentives. Considering ethnic groups, Qataris mainly oppose DR participation, whereas other ethnic groups prefer financial incentives when participating in DR programs. No specific pattern was observed for household income level and DR participation. Finally, plots in the last row show the impact of waived electricity bills on energy consumption based on gender, ethnicity, and income level. According to the results, a higher proportion of female participants believed that waived electricity bills would not change their energy use. Moreover, Arab and Indian ethnic groups believed that waving electricity bills could increase their usage, whereas other groups believed otherwise. Last, for high-income respondents, the possibility of an increase in energy use is less likely, whereas, for lower-income groups, there is a higher possibility of an increase in energy consumption.
Figure 33 shows insights concerning ratepayers' willingness to participate in DR programs. Apartment residents are considerably more inclined to participate in DR, whereas villa owners mostly do not exhibit any interest. Rental home residents demonstrate an interest in DR participation, whereas most homeowners show no interest. Finally, if the building is an oldstyle building, the resident shows more inclination toward DR programs.

\section{Conclusion}

In this work, we conducted an empirical and analytical study based on a sample of 2200 participants in Doha, Qatar, to study the impact of demographic, socioeconomic, and behavioral factors on human-building interactions. The research focused primarily on the idea of leveraging human-oriented factors to reshape energy policy and provide more specific and purposeful guidelines for incorporating social and human characteristics into energy strategic planning and mitigating the uncertainties associated with human dimensions. Numerous interdependencies were analyzed to develop intentional measures to enhance energy policy based on the target society's features.

The $k$-means clustering method was used to classify survey participants into two categories of high and low ratepayer classes based on normalized energy use per area. According to the findings of a feature relevance analysis, household costs, age structure, and ethnicity all provide sufficient information to identify family consumption patterns. Additionally, human attitude and behavioral traits, which are unrelated to demographic and socioeconomic variables, provide sufficient variance to distinguish between the two consumption patterns. This information can help refocus the concentration on specific social communities to raise awareness or establish interventions to alleviate the negative impacts of high consumption. For example, community- 

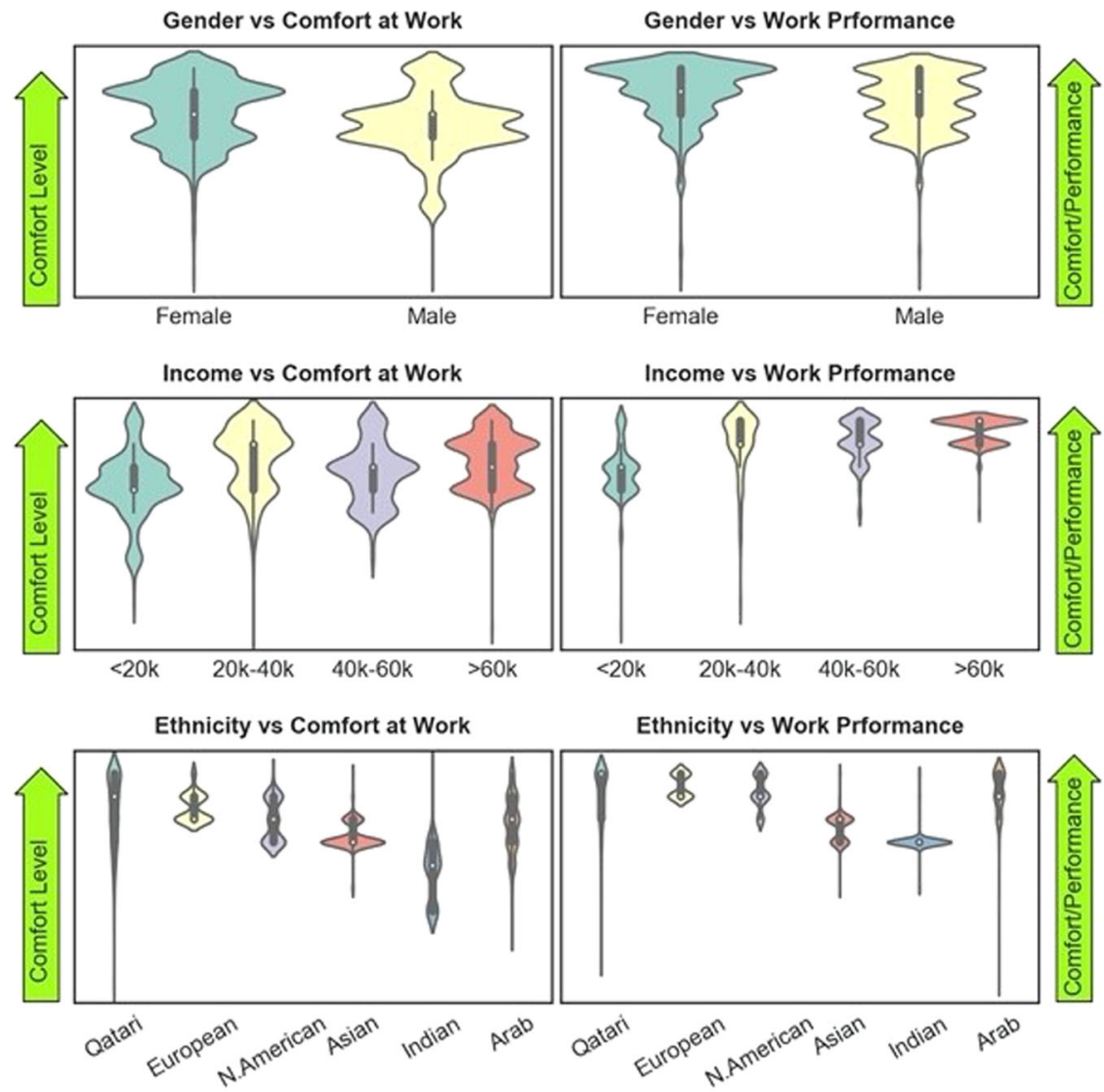

Fig. 28 Respondents' perceived comfort at work and how the comfort level impacts their work performance and productivity. Associations between demographic factors and participants' perceived thermal comfort at work (left column plots) and indoor comfort importance on the respondent's work performance (right column plots).

(a)

(b)

(c)

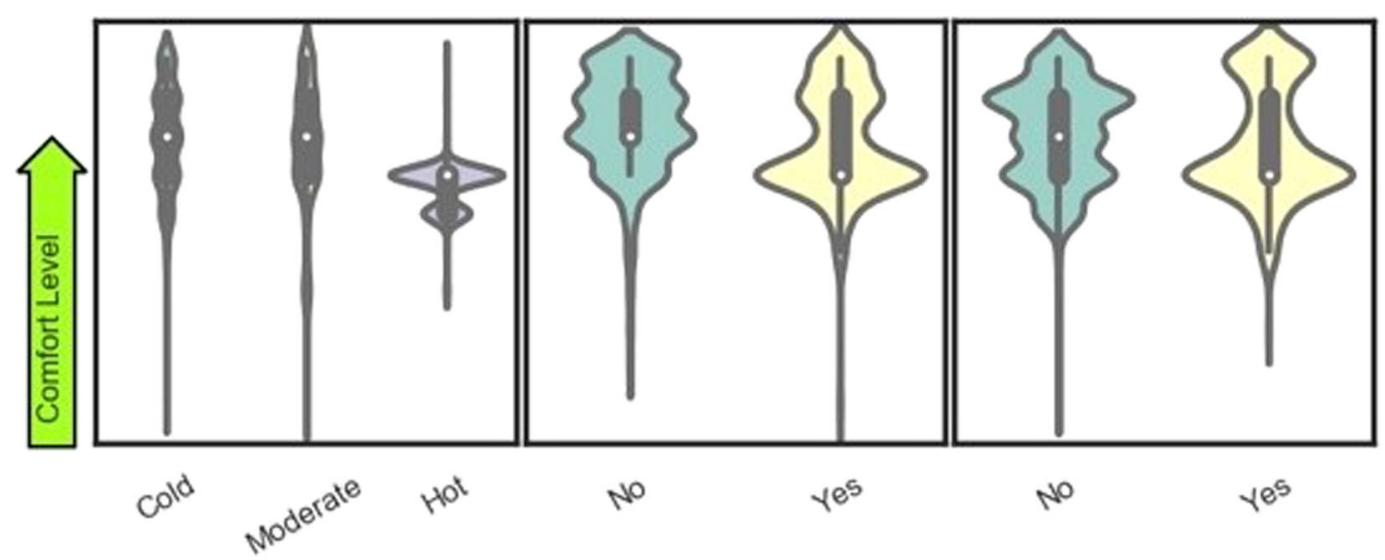

Fig. 29 Correlations between indoor environment preference and human-building interactions with perceived comfort level at work. Relationship between the respondents' perceived comfort with (a) a preferred indoor temperature, (b) a tendency toward thermostat override, and (c) a tendency toward opening windows.

based media campaigns should raise energy awareness, or spatiotemporal energy pricing with increased granularity should be considered to limit electricity usage. There were noticeable trends in reported interior comfort levels, the importance of the indoor environment to the user's well-being, and human-building interactions when demographic, socioeconomic, and building aspects were considered. This understanding may aid in determining how to prioritize financial incentives based on community characteristics to increase well-being inbuilt settings and minimize negative human-building interactions caused by human discomfort. Additionally, it was discovered that attitudes toward climate change awareness, self-responsibility elements in energy usage, and home energy efficiency drivers are strongly influenced by demographic and socioeconomic characteristics. Finally, it was discovered that human characteristics such as gender, ethnic origin, and income level are associated with the influence of 
(a)

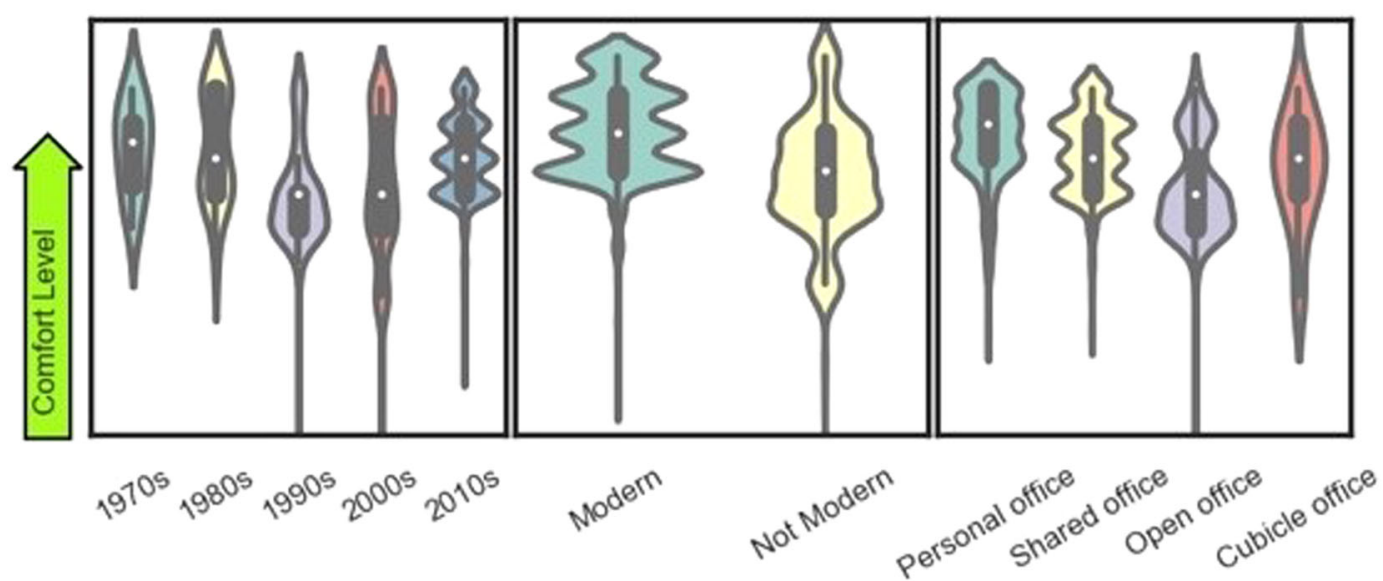

Fig. 30 Impact of building construction and attributes on the perceived comfort level. Relationship between the respondent's perceived comfort and a workplace construction year, b workplace style, and $\mathbf{c}$ workplace type.
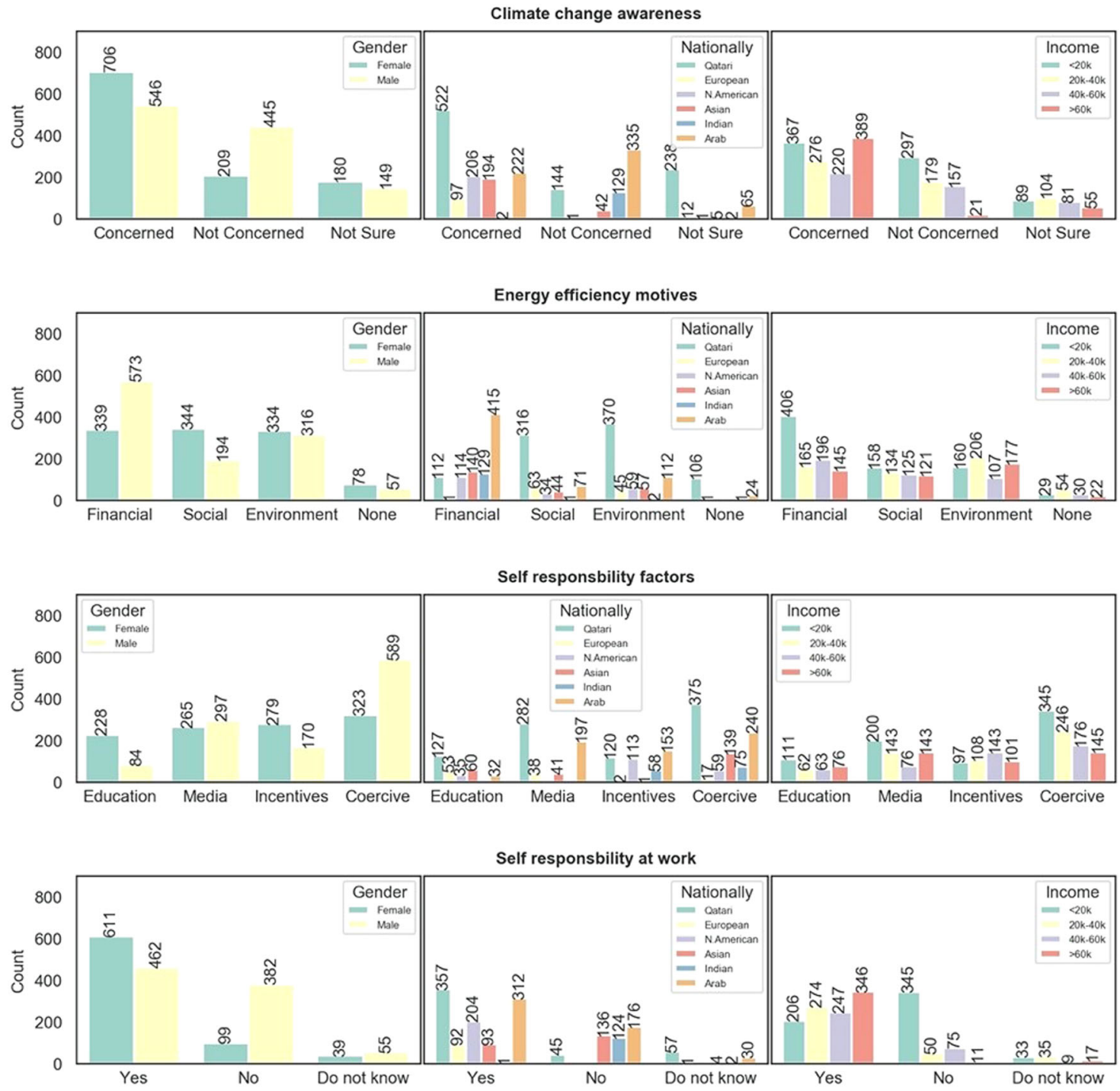

Fig. 31 Intercorrelation between respondents' attitudes and key demographic/socioeconomic factors. 

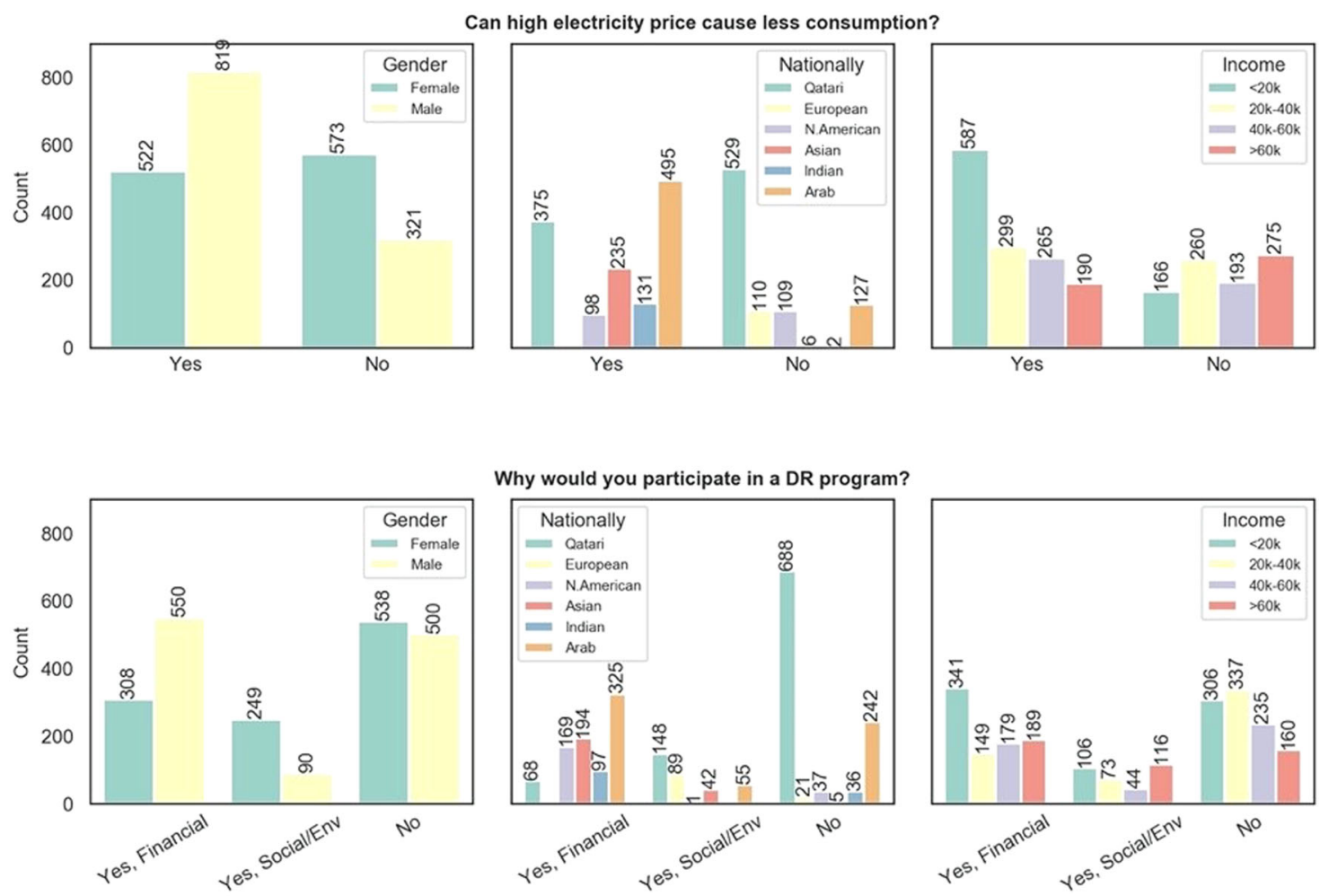

Why would you participate in a DR program?
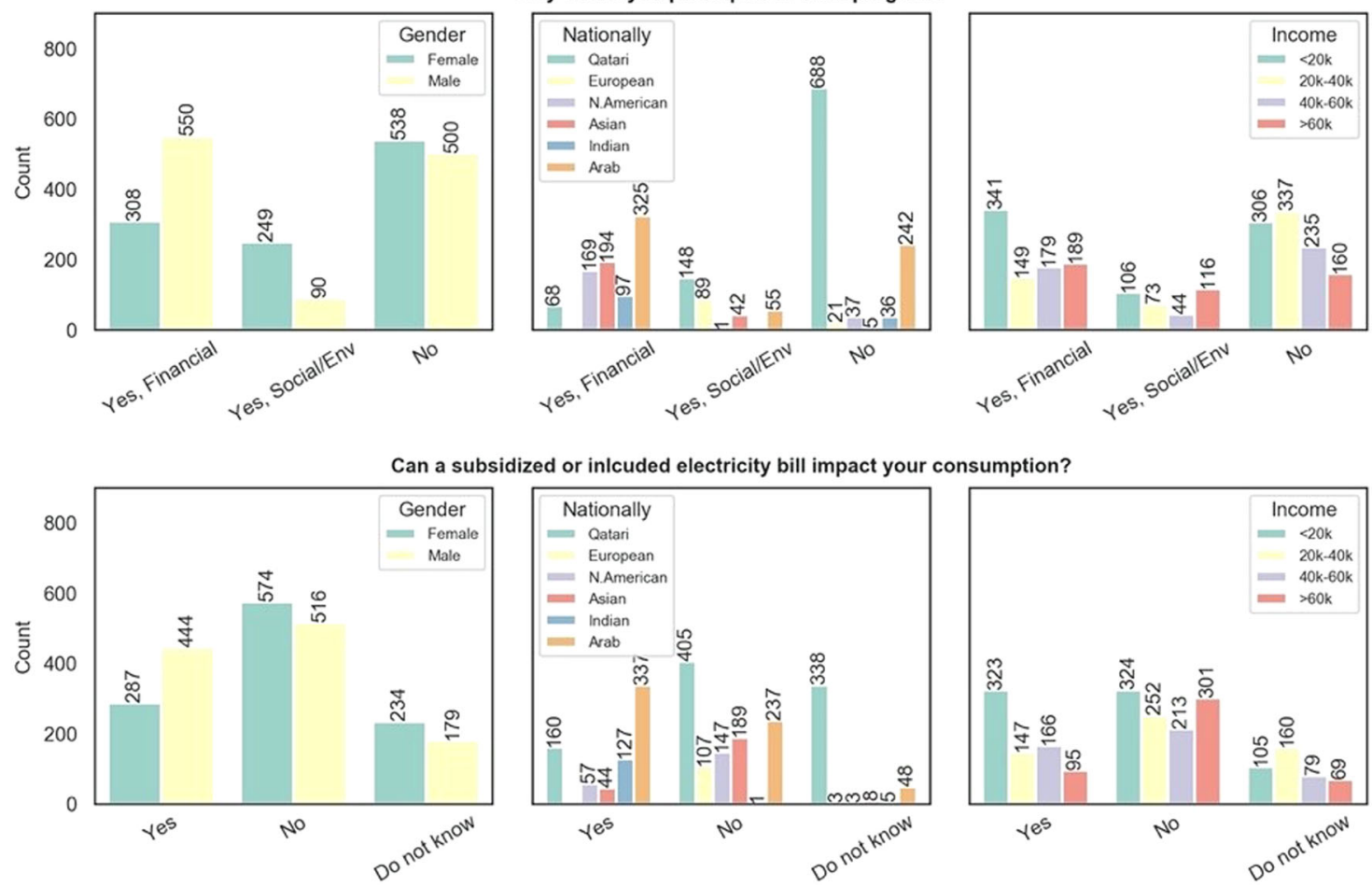

Fig. 32 Interdependencies between demographic/socioeconomic factors and financial drivers of home energy consumption and DR participation willingness.
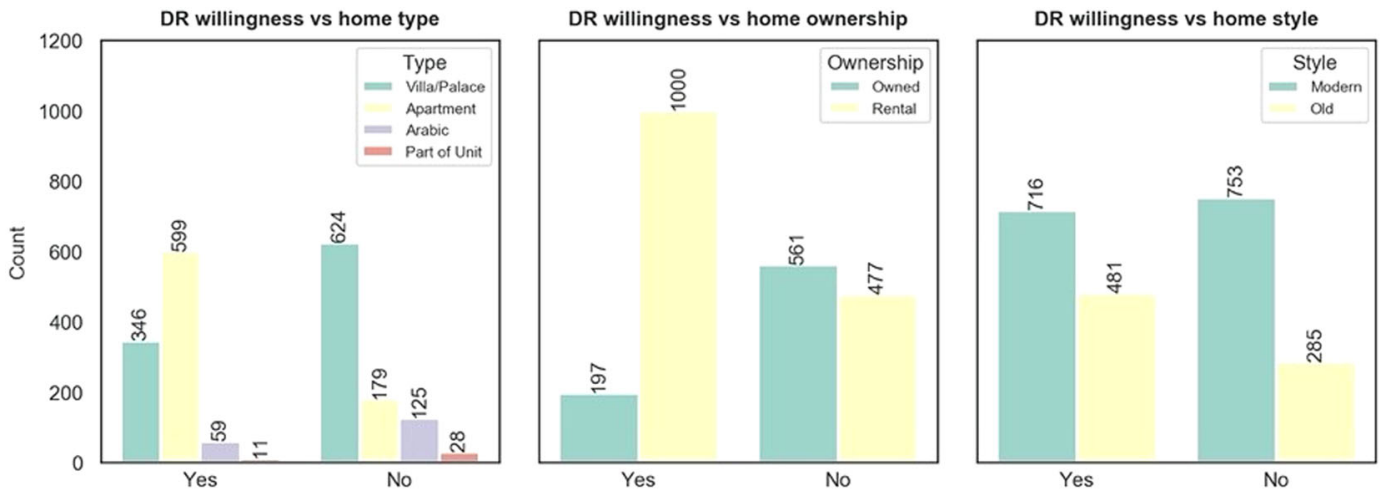

Fig. 33 DR willingness association with building attributes with respect to home type, ownership, and style. 
financial drivers on residential energy consumption, as well as users' willingness to participate in DR programs with monetary incentives. In general, apartment occupants were more inclined to participate, homeowners were strongly opposed, and owners of older-style buildings exhibited a greater willingness to participate in DR initiatives.

Recently, Qatar and other GCC countries have introduced numerous initiatives to reduce energy consumption, including (Lahn et al., 2013; Ayoub et al., 2014): (i) establishing institutions through the cooperation of foreign companies, local banks, and national funds aimed at creating innovative solar projects and adequate industrial infrastructure; (ii) establishing R\&D infrastructure (e.g., Qatar Science \& Technology Park) by implementing national programs aimed at reducing GHG emissions; (iii) establishing a Tarsheed campaign by KAHRAMAA (Tarsheed is a term referring to both "guidance" and "rationalization"). The campaign resulted in a $10 \%$ decrease in electricity consumption per capita compared to 2012. However, and according to the findings of this study, a diversified society, such as the GCC union, with a high share of expatriates and noncitizen populations, will be unable to properly implement energy strategy plans that are linked with social, economic, and environmental sustainability aims if human dimensions are overlooked. That is, in addition to aggressive targets for technology penetration and diversification of the economy, decision-makers must consider human-centered actions such as targeted electricity pricing, community-based awareness, and education, incentive modeling to promote building energy efficiency, establishing new social/personal norms and values, and increasing a sense of responsibility. Lawmakers must overcome regulatory impediments to energy pricing plans and subsidies. Taxation and enforcement must be reevaluated in the region's real estate markets to determine the influence of marketing efforts such as utility bill deferment offers on residential energy use (Angizeh et al., 2021b). Energy efficiency plans must include financial incentives and refunds to entice the private sector. Infrastructure and legislation must be in place to ensure DR program quality and address critical concerns such as consumer privacy, reliability, and security. Apart from social and behavioral studies, it is understood that multidisciplinary methods are critical for properly engaging in the environmental, economic, political, and technological dimensions of this transformation.

Additional studies are required, including an analysis of the new data updates covering the COVID-19 period and an assessment of electricity consumption trends. In addition, an analysis of the consumption trends for the various end-uses and a more detailed decomposition analysis should be included in future studies.

As a direction for future research, further studies is needed, including an analysis of the new data updates covering the Covid19 period and an assessment of electricity consumption trends. In addition, an analysis of the consumption trends for the various end-uses and a more detailed decomposition analysis should be included in future studies.

\section{Data availability}

The datasets generated The datasets generated during and/or analyzed during the current study are not publicly available due to (i) collaborative data collection between two institutions (Qatar University and Qatar General Electricity and Water Corporation), and (ii) to protect the anonymity of the respondents but are available from the corresponding author on reasonable request.

Received: 27 November 2020; Accepted: 16 September 2021; Published online: 26 October 2021

\section{References}

Abul SJ, Satrovic E, Muslija A (2019) The link between energy consumption and economic growth in Gulf Cooperation Council countries. Mater Test 9:38-45. https://doi.org/10.1515/mt-1999-417-807

Afzalan M, Jazizadeh F, Wang J (2019) Self-configuring event detection in electricity monitoring for human-building interaction. Energy Build 187:95-109. https://doi.org/10.1016/J.ENBUILD.2019.01.036

Al-Marri W, Al-Habaibeh A, Watkins M (2018) An investigation into domestic energy consumption behaviour and public awareness of renewable energy in Qatar. Sustain Cities Soc 41:639-646. https://doi.org/10.1016/j.scs.2018.06.024

Alalouch C, Saleh MS, Al-Saadi S (2016) Energy-efficient house in the GCC region. Procedia - Soc Behav Sci 216:736-743. https://doi.org/10.1016/ j.sbspro.2015.12.071

Alfadala HE, El-Halwagi MM (2017) Qatar's chemical industry: monetizing natural gas. Chem Eng Prog 113:38-41

Angizeh F, Ghofrani A, Zaidan E, Jafari MA (2021a) Resilience-oriented behindthe-meter energy storage system evaluation for mission-critical facilities. IEEE Access. https://doi.org/10.1109/ACCESS.2021.3085410. IEEE 2021

Angizeh F, Ghofrani A, Zaidan E, Jafari MA (2021b) On evaluation of onsite energy storage for various end-use facilities with utility bill management, arbitrage, and frequency regulation opportunities. In: 2021 IEEE Power and Energy Society Innovative Smart Grid Technologies Conference, ISGT. IEEE 2021

Appel-Meulenbroek R, Danivska V (2021) A handbook of theories on designing alignment between people and the office environment. Routledge

Ayoub N, Musharavati F, Pokharel S, Gabbar HA (2014) Energy consumption and conservation practices in Qatar-a case study of a hotel building. Energy Build 84:55-69. https://doi.org/10.1016/j.enbuild.2014.07.050

Bamberg S (2013) Changing environmentally harmful behaviors: a stage model of self-regulated behavioral change. J Environ Psychol 34:151-159. https:// doi.org/10.1016/j.jenvp.2013.01.002

Bednar DJ, Reames TG, Keoleian GA (2017) The intersection of energy and justice: modeling the spatial, racial/ethnic and socioeconomic patterns of urban residential heating consumption and efficiency in Detroit, Michigan. Energy Build 143:25-34. https://doi.org/10.1016/j.enbuild.2017.03.028

Bertoldi P (2019) Overview of the European Union policies to promote more sustainable behaviours in energy end-users. Elsevier Inc.

Bertoldi P, Economidou M (2018) EU member states energy efficiency policies for the industrial sector based on the NEEAPs analysis. In: Eceee Industrial Summer Study Proceedings, 2018 June. pp. 117-127. European Council for an Energy Efficient Economy

Bertoldi P, Rezessy S, Oikonomou V (2013) Rewarding energy savings rather than energy efficiency: exploring the concept of a feed-in tariff for energy savings. Energy Policy 56:526-535. https://doi.org/10.1016/j.enpol.2013.01.019

Biresselioglu ME, Demir MH, Rashid A et al. (2019) What are the preferences of household energy use in Pakistan?: findings from a national survey. Energy Build 205:109538. https://doi.org/10.1016/j.enbuild.2019.109538

Blok K, Afanador A, Van Der Hoorn I et al. (2020) Assessment of sectoral greenhouse gas emission reduction potentials for 2030. Energies 13:1-24. https://doi.org/10.3390/en13040943

Boucher JL, Araújo K, Hewitt E (2018) Do education and income drive energy audits? A socio-spatial analysis of New York State. Resour Conserv Recycl 136:355-366. https://doi.org/10.1016/j.resconrec.2018.05.009

Bradshaw JL, Bou-Zeid E, Harris RH (2016) Greenhouse gas mitigation benefits and cost-effectiveness of weatherization treatments for low-income, American, urban housing stocks. Energy Build 128:911-920. https://doi.org/ 10.1016/j.enbuild.2016.07.020

Breiman L (1996) Bagging predictors. Mach Learn 24:123-140. https:/doi.org/ 10.1023/A:1018054314350

Breiman L (1984) Classification and regression trees. Cytometry 8:534-535. https:// doi.org/10.1002/cyto. 990080516

U.S. department of energy (2012). SEE Action Series: Energy Audit and RetroCommissioning Policies for Public and Commercial Buildings

Cagno E, Worrell E, Trianni A, Pugliese G (2012) Dealing with barriers to industrial energy efficiency: an innovative taxonomy. In: ECEEE 2012 industrial summer study. pp. 759-770. IEEE. 2012

Calì D, Osterhage T, Streblow R, Müller D (2016) Energy performance gap in refurbished German dwellings: lesson learned from a field test. Energy Build 127:1146-1158. https://doi.org/10.1016/j.enbuild.2016.05.020

Carr J, Brissette A, Ragaini E, Omati L (2017) Managing smart grids using price responsive smart buildings. Energy Procedia 134:21-28. https://doi.org/ 10.1016/j.egypro.2017.09.593

D'Oca S, Hong T, Langevin J (2018a) The human dimensions of energy use in buildings: a review. Renew Sustain Energy Rev 81:731-742. https://doi.org/ 10.1016/j.rser.2017.08.019

D’Oca S, Pisello AL, De Simone M et al. (2018b) Human-building interaction at work: findings from an interdisciplinary cross-country survey in Italy. Build Environ 132:147-159. https://doi.org/10.1016/j.buildenv.2018.01.039 
Darby SJ (2020) Demand response and smart technology in theory and practice: customer experiences and system actors. Energy Policy 143:111573. https:// doi.org/10.1016/j.enpol.2020.111573

Delzendeh E, Wu S, Lee A, Zhou Y (2017) The impact of occupants' behaviours on building energy analysis: a research review. Renew Sustain Energy Rev 80:1061-1071. https://doi.org/10.1016/j.rser.2017.05.264

Drehobl A, Ross L (2016) Lifting the high energy burden in America's largest cities: how energy efficiency can improve low income and underserved communities. American Council for an Energy-Efficient Economy (ACEEE)

Földváry Ličina V, Cheung T, Zhang H et al. (2018) Development of the ASHRAE global thermal comfort Database II. Build Environ 142:502-512. https:// doi.org/10.1016/j.buildenv.2018.06.022

Franke M, Nadler C (2019) Energy efficiency in the German residential housing market: its influence on tenants and owners. Energy Policy 128:879-890. https://doi.org/10.1016/j.enpol.2019.01.052

Guerra-Santin O, Romero Herrera N, Cuerda E, Keyson D (2016) Mixed methods approach to determine occupants' behaviour-analysis of two case studies. Energy Build 130:546-566. https://doi.org/10.1016/j.enbuild.2016.08.084

Hassine MB, Harrathi N (2017) The causal links between economic growth, renewable energy, financial development and foreign trade in Gulf Cooperation Council Countries. Int J Energy Econ Policy 7:76-85

Hewitt E, Wang Y (2020) Understanding the drivers of national-level energy audit behavior: demographics and socioeconomic characteristics. Sustain 12: https://doi.org/10.3390/su12052059

Heydarian A, McIlvennie C, Arpan L et al. (2020) What drives our behaviors in buildings? A review on occupant interactions with building systems from the lens of behavioral theories. Build Environ 179:106928. https://doi.org/ 10.1016/j.buildenv.2020.106928

Hong T, Chen CF, Wang Z, Xu X (2020) Linking human-building interactions in shared offices with personality traits. Build Environ 170:106602. https:// doi.org/10.1016/J.BUILDENV.2019.106602

Hong T, Yan D, D'Oca S, Chen CF (2017) Ten questions concerning occupant behavior in buildings: the big picture. Build Environ 114:518-530. https:// doi.org/10.1016/j.buildenv.2016.12.006

Hu S, Guo S, Yan D (2019) Going beyond policies focused on building energy efficiency technologies-evidences and lessons from China. In: Eceee Summer Study Proceedings, June 2019. pp. 293-302

Ida T, Motegi N, Ushifusa Y (2019) Behavioral study of personalized automated demand response in the workplace. Energy Policy 132:1009-1016. https:// doi.org/10.1016/j.enpol.2019.06.029

Jafari MA, Zaidan E, Ghofrani A et al. (2020) Improving building energy footprint and asset performance using digital twin technology. IFAC-PapersOnLine 53:386-391. https://doi.org/10.1016/J.IFACOL.2020.11.062

Jia M, Srinivasan RS, Raheem AA (2017) From occupancy to occupant behavior: an analytical survey of data acquisition technologies, modeling methodologies and simulation coupling mechanisms for building energy efficiency. Renew Sustain Energy Rev 68:525-540. https://doi.org/10.1016/j.rser.2016.10.011

Jin X, Han J (2010) In: Sammut C, Webb GI (eds). K-means clustering BTencyclopedia of machine learning. Springer US, Boston, MA, pp. 563-564.

Karjalainen S (2007) Gender differences in thermal comfort and use of thermostats in everyday thermal environments. Build Environ 42:1594-1603. https:// doi.org/10.1016/j.buildenv.2006.01.009

Kern F, Kivimaa P, Martiskainen M (2017) Policy packaging or policy patching? The development of complex energy efficiency policy mixes. Energy Res Soc Sci 23:11-25. https://doi.org/10.1016/j.erss.2016.11.002

Konstantakopoulos IC, Barkan AR, He S et al. (2019) A deep learning and gamification approach to improving human-building interaction and energy efficiency in smart infrastructure. Appl Energy 237:810-821. https://doi.org/ 10.1016/j.apenergy.2018.12.065

Kontokosta CE, Reina VJ, Bonczak B (2020) Energy cost burdens for low-income and minority households: evidence from energy benchmarking and audit data in five U.S. Cities. J Am Plan Assoc 86:89-105. https://doi.org/10.1080/ 01944363.2019 .1647446

Labanca N, Bertoldi P (2018) Beyond energy efficiency and individual behaviours: policy insights from social practice theories. Energy Policy 115:494-502. https://doi.org/10.1016/j.enpol.2018.01.027

Lacroix K, Gifford R (2018) Psychological Barriers to Energy Conservation Behavior: The Role of Worldviews and Climate Change Risk Perception. Environ Behav 50:749-780. https://doi.org/10.1177/0013916517715296

Lahn G, Stevens P, Preston F (2013) Saving oil and gas in the Gulf. Chatham House (The Royal Institute of International Affairs), pp. 1-53

Lee JA, Bach CK, Bradshaw C (2018) CFD case study: heat exchanger inlet air velocity distribution for ducted tests in a psychrometric chamber (ASHRAE RP-1785). In: International Refrigeration Air Conditioning Conference, Purdue, vol 1. pp. 1-10. Taylor \& Francis publisher. 2018

Lin HW, Hong T (2013) On variations of space-heating energy use in office buildings. Appl Energy 111:515-528. https://doi.org/10.1016/.japenergy.2013.05.040
Lu S, Pang B, Qi Y, Fang K (2018) Field study of thermal comfort in non-airconditioned buildings in a tropical island climate. Appl Ergon 66:89-97. https://doi.org/10.1016/j.apergo.2017.08.008

Malekpour Koupaei D, Song T, Cetin KS, Im J (2020) An assessment of opinions and perceptions of smart thermostats using aspect-based sentiment analysis of online reviews. Build Environ 170:106603. https://doi.org/10.1016/ j.buildenv.2019.106603

Masoso OT, Grobler LJ (2010) The dark side of occupants' behaviour on building energy use. Energy Build 42:173-177. https://doi.org/10.1016/ j.enbuild.2009.08.009

Masson-Delmotte V, Zhai P, Pörtner H-O, et al. (2019) Global warming of $1.5^{\circ} \mathrm{C}$ An IPCC Special Report on the impacts of global warming of $1.5^{\circ} \mathrm{C}$ above preindustrial levels and related global greenhouse gas emission pathways, in the context of strengthening the global response to the threat of climate change, sustainable development, and efforts to eradicate poverty Edited by Science Officer Science Assistant Graphics Officer Working Group I Technical Support Unit

Mills B, Schleich J (2012) Residential energy-efficient technology adoption, energy conservation, knowledge, and attitudes: an analysis of European countries. Energy Policy 49:616-628. https://doi.org/10.1016/j.enpol.2012.07.008

Ming R, Yu W, Zhao X et al. (2020) Assessing energy saving potentials of office buildings based on adaptive thermal comfort using a tracking-based method. Energy Build 208:109611. https://doi.org/10.1016/j.enbuild.2019.109611

Mofidi F, Akbari H (2017) Personalized energy costs and productivity optimization in offices. Energy Build 143:173-190. https://doi.org/10.1016/j.enbuild.2017.03.018

Moghaddasi H, Culp C, Vanegas J, Ehsani M (2021) Net zero energy buildings: variations, clarifications, and requirements in response to the Paris Agreement

Mujan I, Anđelković AS, Munćan V et al. (2019) Influence of indoor environmental quality on human health and productivity - a review. J Clean Prod 217:646-657. https://doi.org/10.1016/j.jclepro.2019.01.307

Nazemi SD, Jafari MA, Zaidan E (2021a) An incentive-based optimization approach for load scheduling problem in smart building communities. Buildings 11:237. https://doi.org/10.3390/BUILDINGS11060237

Nazemi SD, Zaidan E, Jafari MA(2021) The impact of occupancy-driven models on cooling systems in commercial buildings Energies 14:1722. https://doi.org/ 10.3390/EN14061722

Nematchoua MK, Yvon A, Roy SEJ et al (2019) A review on energy consumption in the residential and commercial buildings located in tropical regions of Indian Ocean: a case of Madagascar island. J Energy Storage 24: https:// doi.org/10.1016/j.est.2019.04.022

Nembrini J, Lalanne D (2017) Human-building interaction: When the machine becomes a building. In: IFIP Conference on Human-Computer Interaction. pp 348-369

Niamir L, Filatova T, Voinov A, Bressers H (2018) Transition to low-carbon economy: assessing cumulative impacts of individual behavioral changes. Energy Policy 118:325-345. https://doi.org/10.1016/j.enpol.2018.03.045

Nikolopoulou C, Azar E (2015) An occupancy-driven framework to optimize energy consumption and human comfort in a group of buildings. In: 14th Conference of International Building Performance Simulation Association, Hyderabad, India, December 7-9, 2015.

Nilsson A, Lazarevic D, Brandt N, Kordas O (2018) Household responsiveness to residential demand response strategies: results and policy implications from a Swedish field study. Energy Policy 122:273-286. https://doi.org/10.1016/ j.enpol.2018.07.044

Parsons KC (2002) The effects of gender, acclimation state, the opportunity to adjust clothing and physical disability on requirements for thermal comfort Energy Build 34:593-599. https://doi.org/10.1016/S0378-7788(02)00009-9

Polese LG, Roth A (2016) EnergyPlus. Department of Energy. https://www.energy.gov/ eere/buildings/downloads/energyplus-0. Accessed 15 Sept 2021

Qiao W, Yin X (2021) Understanding the impact on energy transition of consumer behavior and enterprise decisions through evolutionary game analysis. Sustain Prod Consum 28:231-240

Reames TG (2016) Targeting energy justice: exploring spatial, racial/ethnic and socioeconomic disparities in urban residential heating energy efficiency. Energy Policy 97:549-558. https://doi.org/10.1016/j.enpol.2016.07.048

Rinaldi A, Schweiker M, Iannone F (2018) On uses of energy in buildings: extracting influencing factors of occupant behaviour by means of a questionnaire survey. Energy Build 168:298-308. https://doi.org/10.1016/ j.enbuild.2018.03.045

Safron A, DeYoung CG (2021) Integrating Cybernetic Big Five Theory with the free energy principle: a new strategy for modeling personalities as complex systems. In: Measuring and modeling persons and situations. pp. 617-649. Elsevier. 2021

Salvo A (2018) Electrical appliances moderate households' water demand response to heat Nat Commun 9:1-14. https://doi.org/10.1038/s41467-018-07833-3

Schakib-Ekbatan K, Çakici FZ, Schweiker M, Wagner A (2015) Does the occupant behavior match the energy concept of the building?-analysis of a German naturally ventilated office building. Build Environ 84:142-150. https:// doi.org/10.1016/j.buildenv.2014.10.018 
Schweiker M, Huebner GM, Kingma BRM et al. (2018) Drivers of diversity in human thermal perception-a review for holistic comfort models. Temperature 5:308-342. https://doi.org/10.1080/23328940.2018.1534490

Sembroiz D, Ricciardi S, Careglio D (2018) Chapter 10-a novel cloud-based IoT architecture for smart building automation. In: Ficco M, Palmieri FBT-S, R (eds) Intelligent data-centric systems (ID-CS and CN). Academic Press, pp. 215-233

Seppänen O, Fisk W, Lei Q (2006) Effect of temperature on task performance in office environment. Lawrence Berkeley National Laboratory 11

Sghiouri H, Mezrhab A, Karkri M, Naji H (2018) Shading devices optimization to enhance thermal comfort and energy performance of a residential building in Morocco. J Build Eng 18:292-302. https://doi.org/10.1016/j.jobe.2018.03.018

Singh S, Yassine A (2018) Big data mining of energy time series for behavioral analytics and energy consumption forecasting. Energies 11: https://doi.org/ 10.3390/en11020452

Sintov ND, White LV, Walpole H (2019) Thermostat wars? The roles of gender and thermal comfort negotiations in household energy use behavior. PLoS ONE 14:8-10. https://doi.org/10.1371/journal.pone.0224198

Sorrell S, Schleich J, Scott S, et al. (2000) Reducing barriers to energy efficiency in public and private organizations. Sci Policy Technol Res (SPRU), Univ Sussex, Sussex, UK

Sovacool BK (2014) What are we doing here? Analyzing fifteen years of energy scholarship and proposing a social science research agenda. Energy Res Soc Sci 1:1-29. https://doi.org/10.1016/j.erss.2014.02.003

Srivastava A, Van Passel S, Kessels R et al. (2020) Reducing winter peaks in electricity consumption: a choice experiment to structure demand response programs. Energy Policy 137:111183. https://doi.org/10.1016/j.enpol.2019.111183

Sustar J (2020) ASHRAE history of a system: history of trane's TRACE ${ }^{\text {TM }}$ software. ASHRAE Trans 126:640-643

Thiaux Y, Dang TT, Schmerber L et al. (2019) Demand-side management strategy in stand-alone hybrid photovoltaic systems with real-time simulation of stochastic electricity consumption behavior. Appl Energy 253:113530. https:// doi.org/10.1016/j.apenergy.2019.113530

Thompson D, Burman E, Mumovic D, Davies M (2021) Managing the risk of the energy performance gap in non-domestic buildings. Build Serv Eng Res Technol https://doi.org/10.1177/01436244211008319

Tzeiranaki ST, Bertoldi P, Diluiso F et al. (2019) Analysis of the EU residential energy consumption: trends and determinants. Energies 12: https://doi.org/ $10.3390 /$ en 12061065

Victor DG, Edenhofer O (2014) AR5 Climate Change 2014: Mitigation of Climate Change. Cambridge University Press

UNESCWA (2017) The Demographic Profile of Qatar Population TrendsMortality-Fertility-Age Structure-Urbanization-International MigrationEducation and Youth Unemployment Population Trends Mortality

Zaidan E, Abulibdeh A (2020) Master Planning and the Evolving Urban Model in the Gulf Cities: Principles, Policies, and Practices for the Transition to Sustainable Urbanism. Planning Practice \& Research 36:193-215. https://doi.org/ $10.1080 / 02697459.2020 .1829278$

Zaidan E, Al-Saidi M, Hammad SH (2019) Sustainable development in the Arab world-is the Gulf Cooperation Council (GCC) region fit for the challenge? Dev Pract 29:670-681
Zaidan E, Ghofrani A, Dokaj E (2021) Analysis of human-building interactions in office environments: to what extent energy saving boundaries can be displaced? Front Energy Res 0:450. https://doi.org/10.3389/FENRG.2021.715478

Zhang Y, Bai X, Mills FP (2020) Characterizing energy-related occupant behavior in residential buildings: Evidence from a survey in Beijing, China. Energy Build 214: https://doi.org/10.1016/j.enbuild.2020.109823

Zhao D, McCoy AP, Du J et al. (2017) Interaction effects of building technology and resident behavior on energy consumption in residential buildings. Energy Build 134:223-233. https://doi.org/10.1016/j.enbuild.2016.10.049

Zhao HX, Magoulès F (2012) A review on the prediction of building energy consumption. Renew Sustain Energy Rev 16:3586-3592. https://doi.org/ 10.1016/j.rser.2012.02.049

\section{Acknowledgements}

This publication was made possible by an NPRP award [NPRP11S-1228-170142] from the Qatar National Research Fund (a member of Qatar Foundation). The statements made herein are solely the responsibility of the authors. The publication of this article was funded by the Qatar National Library.

\section{Competing interests}

The authors declare no competing interests.

\section{Additional information}

Supplementary information The online version contains supplementary material available at https://doi.org/10.1057/s41599-021-00904-9.

Correspondence and requests for materials should be addressed to Esmat Zaidan.

Reprints and permission information is available at http://www.nature.com/reprints

Publisher's note Springer Nature remains neutral with regard to jurisdictional claims in published maps and institutional affiliations.

Open Access This article is licensed under a Creative Commons Attribution 4.0 International License, which permits use, sharing, adaptation, distribution and reproduction in any medium or format, as long as you give appropriate credit to the original author(s) and the source, provide a link to the Creative Commons license, and indicate if changes were made. The images or other third party material in this article are included in the article's Creative Commons license, unless indicated otherwise in a credit line to the material. If material is not included in the article's Creative Commons license and your intended use is not permitted by statutory regulation or exceeds the permitted use, you will need to obtain permission directly from the copyright holder. To view a copy of this license, visit http://creativecommons.org/ licenses/by/4.0/.

(C) The Author(s) 2021 